\title{
Representation of tropical deep convection in atmospheric models - Part 1: Meteorology and comparison with satellite observations
}

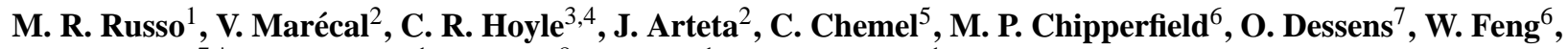 \\ J. S. Hosking ${ }^{7, *}$, P. J. Telford ${ }^{1}$, O. Wild ${ }^{8}$, X. Yang ${ }^{1}$, and J. A. Pyle ${ }^{1}$ \\ ${ }^{1}$ NCAS-Climate, Centre for Atmospheric Science, University of Cambridge, Cambridge, UK \\ ${ }^{2}$ Centre National de Recherches Météorologique/Groupe d'étude de l'Atmosphère Météorologique, Météo-France and \\ CNRS, Toulouse, France \\ ${ }^{3}$ Department of Geosciences, University of Oslo, Norway \\ ${ }^{4}$ Institute for Atmospheric and Climate Science, ETH Zurich, Zurich, Switzerland \\ ${ }^{5}$ NCAS-Weather, Centre for Atmospheric and Instrumentation Research, University of Hertfordshire, Hatfield, UK \\ ${ }^{6}$ Institute for Climate and Atmospheric Science, School of Earth and Environment, University of Leeds, UK \\ ${ }^{7}$ Centre for Atmospheric Science, University of Cambridge, Cambridge, UK \\ ${ }^{8}$ Lancaster Environment Centre, Lancaster University, UK \\ *now at: British Antarctic Survey, Cambridge, UK
}

Received: 19 July 2010 - Published in Atmos. Chem. Phys. Discuss.: 19 August 2010

Revised: 12 February 2011 - Accepted: 18 February - Published: 25 March 2011

\begin{abstract}
Fast convective transport in the tropics can efficiently redistribute water vapour and pollutants up to the upper troposphere. In this study we compare tropical convection characteristics for the year 2005 in a range of atmospheric models, including numerical weather prediction (NWP) models, chemistry transport models (CTMs), and chemistry-climate models (CCMs). The model runs have been performed within the framework of the SCOUT-O3 (Stratospheric-Climate Links with Emphasis on the Upper Troposphere and Lower Stratosphere) project. The characteristics of tropical convection, such as seasonal cycle, land/sea contrast and vertical extent, are analysed using satellite observations as a benchmark for model simulations. The observational datasets used in this work comprise precipitation rates, outgoing longwave radiation, cloud-top pressure, and water vapour from a number of independent sources, including ERA-Interim analyses. Most models are generally able to reproduce the seasonal cycle and strength of precipitation for continental regions but show larger discrepancies with observations for the Maritime Continent region. The frequency distribution of high clouds from models and observations is calculated using highly temporally-resolved (up to 3-hourly) cloud top data. The percentage of clouds above $15 \mathrm{~km}$ varies significantly between the models. Vertical profiles of water vapour in the upper troposphere-lower stratosphere (UTLS)
\end{abstract}

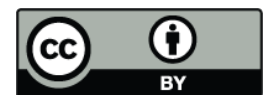

Correspondence to: M. Russo (maria.russo@atm.ch.cam.ac.uk) show large differences between the models which can only be partly attributed to temperature differences. If a convective plume reaches above the level of zero net radiative heating, which is estimated to be $\sim 15 \mathrm{~km}$ in the tropics, the air detrained from it can be transported upwards by radiative heating into the lower stratosphere. In this context, we discuss the role of tropical convection as a precursor for the transport of short-lived species into the lower stratosphere.

\section{Introduction}

Tropical deep convection is recognised as an important atmospheric feature acting on the global water cycle and chemical composition of the atmosphere. The vertical extent of convective plumes and their direct impact on stratospheric composition and water vapour has been debated extensively in the literature (Danielsen, 1993; Smith et al., 2006; Ricaud et al., 2007; Levine et al., 2007; Grosvenor et al. 2007; Berthet et al., 2007; Schiller et al., 2009; Chemel et al., 2009; Hosking et al., 2010). Water vapour in the stratosphere has a strong impact on the radiative budget of the atmosphere and understanding the links between the strength of tropical convection and the water vapour budget in the UTLS is crucial if we want to predict stratospheric feedbacks on surface temperature in a changing climate (Solomon et al., 2010). Convective events in the Tropics can routinely reach an altitude of $11-14 \mathrm{~km}$, corresponding on average to

Published by Copernicus Publications on behalf of the European Geosciences Union. 
220-150 hPa (Gettelman et al., 2002; Alcala and Dessler, 2002) and occasionally can reach above the level of neutral buoyancy and penetrate directly above the tropopause at 16-17 km ("overshooting" convection, e.g. Highwood and Hoskins, 1998; Liu and Zipser, 2005; Corti et al., 2008; Luo et al., 2008).

The frequency, seasonality and preferential location of deep convection have been investigated using passive sensors from global satellite observations (Tian et al., 2004, 2005; Liu and Zipser, 2005; Rossow and Pearl, 2007; Liu, 2007; Liu et al., 2007; Hong et al., 2008; Kelley et al., 2010). Recent techniques involving active sensors, such as the the cloud profiling radar on board of CloudSat and the cloud aerosol lidar from CALIPSO, have provided more accurate estimates of high cloud fractions (Luo et al., 2008; Wu et al., 2009). Both instruments are sensitive to small cloud-size particles and therefore show generally larger fractions of high clouds compared to passive sensors (Wu et al., 2009).

Although the fraction of convective events which directly penetrate into the lower stratosphere is thought to be very small (Liu and Zipser, 2005; Rossow and Pearl, 2007; Luo et al., 2008), deep convection can still play a role in determining the stratospheric composition through its interaction with the tropical tropopause layer (TTL). The TTL is a transitional layer in the tropics connecting the upper troposphere $(8-10 \mathrm{~km})$ to the lower stratosphere $(17 \mathrm{~km})$ and it has been defined, for example, by Highwood and Hoskins (1998), Folkins et al. (1999), Gettelman and Forster (2002), Fueglistaler et al. (2009). This layer is of particular importance in troposphere-stratosphere exchanges, since it is from the TTL that chemical species and water vapour enter the lower stratosphere where they can influence the stratospheric composition on the global scale (Folkins et al., 1999; Sherwood and Dessler, 2001; Fueglistaler et al., 2004; Levine et al., 2007). Air from the boundary layer can be efficiently transported by deep convection into the TTL within a few hours (e.g. Pickering et al., 1996; Marécal et al., 2006). In the upper part of the TTL, i.e. above the level of zero net radiative heating $(Q=0)$, air parcels can be radiatively transported upward into the stratosphere, with a timescale of months (Gettelmann et al., 2004). The average height of the zero net radiative heating level for clearsky conditions, $\left(Q_{\text {clear }}=0\right)$ has been estimated to be around $15 \mathrm{~km}$ (Folkins et al.,1999; Gettelman et al., 2004; McFarlane et al. 2007), with variations ranging between -0.97 and $0.48 \mathrm{~km}$, depending on location and season (Gettelman et al., 2004). The height of $Q_{\text {clear }}=0$ is also affected by the diurnal cycle of radiation, with values at local noon being 1$1.5 \mathrm{~km}$ lower than the average (Gettelman et al., 2004). Although Gettelman et al. (2004) estimated that the presence of clouds would increase the height of $Q=0$ by $0.1-1.5 \mathrm{~km}$ (depending on cloud height and optical depth), a more comprehensive study by McFarlane et al. (2007) suggested that the effect of clouds on the radiative balance of the atmosphere is rather more complex. McFarlane et al. (2007) used both observations and model calculations to show that the height of $Q=0$ is either the same or up to $2 \mathrm{~km}$ lower than $Q_{\text {clear }}=0$. A similar relation between the height of $Q=0$ and $Q_{\text {clear }}=0$ is also shown in Hosking et al. (2010). We therefore assume that, under most conditions in the tropics, both $Q=0$ and $Q_{\text {clear }}=0$ levels are located at a height of $\sim 15 \mathrm{~km}$ or lower, and an air parcel above $15 \mathrm{~km}$ would be subject to radiative ascent. Tropical convection can therefore affect stratospheric composition not only through direct injection of surface species into the stratosphere, but also through loading of the TTL region above the $Q=0$ level. The frequency and location of convective events reaching above $15 \mathrm{~km}$ are therefore important elements in understanding the transport pathways of surface species and other pollutants to the lower stratosphere.

The vertical transport of tracers by deep convection is recognised to be an important physical process and is included in nearly all types of 3-D atmospheric models. Deep convection covers a large range of spatial scales from individual clouds with horizontal extent of a few square kilometres, to larger systems of several thousands square kilometres. The horizontal resolution of current global models such as Chemistry Transport Models (CTMs), and Chemistry Climate Models (CCMs) is typically $1-2^{\circ}$ or more in latitude/longitude. Global Numerical Weather Prediction (NWP) models have higher resolution with a grid spacing of $\sim 0.5$ to $0.2^{\circ}$ (equivalent to $\sim 60$ to $20 \mathrm{~km}$ ). However, even at these higher horizontal resolutions, deep convection and the associated tracer transport cannot be explicitly represented. Therefore, most models use a parameterisation scheme to represent deep convection and the associated transport. Many such parameterisations have been proposed in the literature (e.g. Arakawa and Schubert, 1974; Tiedtke, 1989; Kain and Fritch, 1990; Grell, 1993; Zhang and McFarlane, 1995). Previous studies showed that model simulations are strongly influenced by the convection parameterisation used (e.g. Mapes et al., 2004; Lawrence and Rasch, 2005; Yano, 2009; Arteta et al., 2009a; Tost et al., 2010). This is known to be a very significant source of uncertainties in global and regional models. The triggering and intensity of convection is also sensitive to the vertical and horizontal resolution of the model (e.g. Rind, 1988; Dequé et al., 1994; Pope et al., 2001; Arteta et al., 2009b). Barret et al. (2010) have recently investigated differences in lightning $\mathrm{NO}_{x}$ production and convective transport in a variety of models, with a specific focus on the West Africa region. Because of differences in horizontal and vertical resolution, and in the treatment of advection and convection, models are likely to provide different locations, frequency and vertical extent of tropical convective events. This can lead to differences in the convective transport of tracers, possibly affecting air composition in the free troposphere and the TTL at the global scale.

Due to the interplay of chemical and dynamical processes, it is difficult to evaluate the model convective transport of chemical species by direct comparison with observed 
chemical fields. So far no attempt has been made to objectively compare deep tropical convection in different types of 3-D models, and to assess the relative role of convective transport on tracers' distribution. This is the first of two papers focusing on the ability of models to represent tropical convection and the associated vertical transport. The simulations used in these two papers were coordinated through a model intercomparison exercise under the European project SCOUT-O3 (http://www.ozone-sec.ch.cam.ac.uk/scout_o3). Two sets of model simulations were performed, the first focused on long-lived tracers, while the second focused on very short-lived tracers and physical processes associated with convection. In this paper we analyse results from the latter, and we restrict our analysis to the meteorological parameters associated to convection with the aim of assessing the models' ability to simulate the seasonal cycle, preferential locations, vertical extent and frequency of deep tropical convection. The analysis of tracer distributions in the Tropics (for both short- and long-lived tracers) can be found in the second paper of this series (Hoyle et al., 2010), which focuses on the relative role of convection in the vertical transport of tracers. The section on convective transport of very short-lived tracers in Hoyle et al. (2010) is therefore consistent with this paper, although additional model data is used for the analysis of long-lived tracers.

Meteorological variables from the model simulations are compared to observations from satellite platforms and reanalysis data. We use more than one observational dataset for each meteorological variable in order to highlight differences between instruments and to provide a rough measure of the uncertainties in the observations. Due to the high computational cost of high resolution model runs, we focus our analysis on a single year. The year 2005 was chosen since measurement campaigns were carried out in South America in February (http://www.pa.op.dlr.de/troccinox/) and North Australia in November and December (Vaughan et al., 2008) which found significant evidence of at least a few convective systems reaching the lower stratosphere. Additionally, there was no strong ENSO signal for 2005. The comparison of observed convective properties with model results provides a useful benchmark to test model performances; this information can in turn help to interpret the results in Hoyle et al. (2010).

Sections 2 and 3 describe the model simulations and satellite datasets used in this study. Section 4 focuses on the convection characteristics observed for the year 2005 and comparison of models with observations. Conclusions are given in Sect. 5.

\section{Description of the model simulations}

Different categories of 3-D models use different approaches to calculate tracer transport. CTMs use 3-D wind fields from an independent model, usually operational analyses and/or forecasts, to perform large-scale transport (also known as advection). For these models the fast vertical transport by deep convection can be either diagnosed from the convective fluxes provided by the independent model or recalculated by the CTM's own convection parameterisation scheme. CCMs and NWP models both use their own dynamical core to calculate 3-D wind fields and the resulting large scale transport. Convective mass fluxes of chemical species are also calculated by the model's convection parameterisation scheme. Some of the models in this study use ECMWF operational analyses and/or forecasts, either to provide direct forcing for tracer transport (i.e. for CTMs), or to relax the model's meteorological fields to the analyses (a technique known as "nudging"). The limited area model in this study also uses ECMWF analyses to constrain the model's meteorology at the lateral boundary and at the model top. In Table 1 we summarize the main features and also differences and similarities in the treatment of convection for the models used in this study. A brief description of the different models follows; the reader is referred to the relevant literature for further details.

Oslo-CTM2 (Berntsen et al., 2006) is a global CTM. It has 40 vertical levels, with hybrid $\sigma$-p coordinates from surface to $2 \mathrm{hPa}(\sim 43 \mathrm{~km})$. The horizontal resolution is $\sim 2.8^{\circ}$ longitude by $\sim 2.8^{\circ}$ latitude. The model uses 3-hourly dynamic, thermodynamical and microphysical fields from forecasts run with ECMWF IFS model (cycle 29) and truncated at $\mathrm{T} 42$ resolution. Surface precipitation rates are output directly from ECMWF IFS forecasts, while convective cloud top heights are defined as the highest model level for which the ECMWF convective mass flux is greater than zero.

FRSGC-UCI CTM (Wild et al., 2003) has a very similar configuration to Oslo-CTM2 except that the lowest 5 model levels are merged into 2, resulting in a total of 37 vertical layers. Further differences between the two models exist on tracer transport and chemistry. Since Oslo-CTM2 and FRSGC-UCI CTM use the same meteorological information, we analyse results from the two models together in this paper.

TOMCAT (Chipperfield, 2006) is a global CTM. It has 31 vertical levels, with hybrid $\sigma$-p coordinates from surface to $10 \mathrm{hPa}(\sim 31 \mathrm{~km})$. The horizontal resolution used in this study is the same as the other CTMs, $\sim 2.8^{\circ}$ longitude by $\sim 2.8^{\circ}$ latitude. The model is forced by 6 -hourly ECMWF operational analyses truncated at T42 resolution. Precipitation rates and cloud top heights are diagnosed by the model convection parameterisation scheme (Stockwell and Chipperfield, 1999) based on Tiedtke et al. (1989). The convective cloud top height is defined as the highest model level at which the buoyancy of an air parcel raising adiabatically from the surface is positive with respect to the environment. Further information on the performance of the TOMCAT convection scheme can be found in Feng et al. (2010).

pTOMCAT (O'Connor et al., 2005) is a CTM with a very similar configuration to TOMCAT. pTOMCAT uses the same forcing files as TOMCAT, and shares the same tracer 
Table 1. Description of model configurations and setup.

\begin{tabular}{|c|c|c|c|c|c|c|}
\hline $\begin{array}{l}\text { Model } \\
\text { Name }\end{array}$ & $\begin{array}{l}\text { Model } \\
\text { Category }\end{array}$ & $\begin{array}{r}\text { Resolution: } \\
\text { Horizontal; } \\
\text { n vertical levels }\end{array}$ & Dynamics & $\begin{array}{l}\text { Nudging } \\
\text { (if applied) }\end{array}$ & $\begin{array}{l}\text { Simulation } \\
\text { period }\end{array}$ & $\begin{array}{l}\text { Convective } \\
\text { parameterisation }\end{array}$ \\
\hline OSLOCTM2 & CTM-global & $\begin{array}{r}\sim 2.8^{\circ} \times 2.8^{\circ} \\
\mathrm{L} 40\end{array}$ & $\begin{array}{l}\text { Off-line } \\
\text { ECMWF }\end{array}$ & N/A & 2005 year & No \\
\hline FRSGCUCI & CTM-global & $\begin{array}{r}\sim 2.8^{\circ} \times 2.8^{\circ} \\
\mathrm{L} 37\end{array}$ & $\begin{array}{l}\text { Off-line } \\
\text { ECMWF }\end{array}$ & N/A & 2005 year & No \\
\hline TOMCAT & CTM-global & $\begin{array}{r}\sim 2.8^{\circ} \times 2.8^{\circ} \\
\mathrm{L} 31\end{array}$ & $\begin{array}{l}\text { Off-line } \\
\text { ECMWF }\end{array}$ & N/A & 2005 year & Tiedtke (1989) \\
\hline pTOMCAT & CTM-global & $\begin{array}{r}\sim 2.8^{\circ} \times 2.8^{\circ} \\
\mathrm{L} 31\end{array}$ & $\begin{array}{l}\text { Off-line } \\
\text { ECMWF }\end{array}$ & N/A & 2005 year & Tiedtke (1989) \\
\hline pTOMCAT_tropical & CTM-global & $\begin{array}{r}\sim 2.8^{\circ} \times 2.8^{\circ} \\
\mathrm{L} 31\end{array}$ & $\begin{array}{l}\text { Off-line } \\
\text { ECMWF }\end{array}$ & N/A & 2005 year & $\begin{array}{l}\text { based on } \\
\text { Tiedtke (1989) }\end{array}$ \\
\hline UMUKCA-UCAM_nud & CCM-global & $\begin{array}{r}\sim 3.7^{\circ} \times 2.5^{\circ} \\
\mathrm{L} 38\end{array}$ & On-line & $\begin{array}{l}\mathrm{U}, \mathrm{V} \text { and } \mathrm{T} \\
\text { from } \mathrm{ECWMF}\end{array}$ & 2005 year & $\begin{array}{l}\text { Gregory and } \\
\text { Rowntree (1990) }\end{array}$ \\
\hline WRF & NWP-global & $\begin{array}{r}\sim 1.9^{\circ} \times 1.2^{\circ} \\
\mathrm{L} 38\end{array}$ & On-line & No & 2005 year & $\begin{array}{l}\text { Janjic } \\
(1994,2000)\end{array}$ \\
\hline UM-UCAM_highres & NWP-global & $\begin{array}{r}\sim 0.8^{\circ} \times 0.5^{\circ} \\
\mathrm{L} 38\end{array}$ & On-line & No & $\begin{array}{l}\text { 2005: Feb, May, } \\
\text { Aug and Nov }\end{array}$ & $\begin{array}{l}\text { Gregory and } \\
\text { Rowntree (1990) }\end{array}$ \\
\hline CATT-BRAMS & NWP-regional & $\begin{array}{r}\sim 0.5^{\circ} \times 0.5^{\circ} \\
\mathrm{L} 39\end{array}$ & On-line & $\begin{array}{l}\text { Lat. Boundary: } \\
U, V, T \text { and } Q \\
\text { from ECMWF }\end{array}$ & $\begin{array}{l}\text { 2005: Feb, Aug } \\
\text { and Nov }\end{array}$ & $\begin{array}{l}\text { Grell and } \\
\text { Dévényi (2002) }\end{array}$ \\
\hline
\end{tabular}

advection and other parameterisation schemes. For this reason, meteorological fields from the current setups of TOMCAT and pTOMCAT are identical and we analyse the results together in this paper. Some differences between the two models exist on the formulation of the chemistry scheme.

pTOMCAT_tropical is a modified version of pTOMCAT CTM, which has the same horizontal and vertical resolution but has been developed specifically for better representation of convective transport in tropical regions (see Feng et al., 2010; Barret et al., 2010). The main changes to the code are summarised as follows: the surface moisture used to trigger convective clouds is derived from the International Satellite Cloud Climatology Project (ISCCP) cloud fractions (Rossow et al., 1996); entrainment rates for the convective column are set to half the value originally suggested by Tiedtke et al. (1989), hence there will be less stable ambient air entrained into the cloud and positive buoyancy is retained to higher altitudes; detrainment rates are set to zero, except at the top of the convective column. As in TOMCAT and pTOMCAT, the convective cloud top height is defined as the highest model level at which the buoyancy of an air parcel raising adiabatically from the surface is positive with respect to the environment.

UMUKCA-UCAM_nud (Telford et al., 2008) and UMUCAM_highres (Petch et al., 2007; Hosking et al., 2010) are based on the UKMO Unified Model (UM). The model is non-hydrostatic with a hybrid $\sigma$-height vertical coordinate and 38 levels from the surface to $39 \mathrm{~km}$. Shallow and deep convection are parameterised with a convective scheme by
Gregory and Rowntree (1990); for deep convection, the thermodynamic closure is based on the reduction of CAPE to zero based on Fritsch and Chappell (1980). Precipitation and cloud microphysics are based on a parametrisation for transfers between the different categories of hydrometeors (Wilson and Ballard, 1999). The convective cloud top is defined as the upper boundary of the last buoyant layer. In these simulations, sea surface temperatures and sea ice from the GISST 2.0 climatology (Parker et al., 1995) are used to constrain the model at the sea surface. The main difference between the two model configurations is the horizontal resolution, the former having a grid spacing of $3.75^{\circ} \times 2.5^{\circ}$ (N48), and the latter with a grid spacing of $0.83^{\circ} \times 0.56^{\circ}$ (N216). A "nudging" technique is applied to the coarser resolution configuration, whereby temperature and horizontal winds are relaxed to 6-hourly ECMWF analyses (Telford et al., 2008). The higher resolution configuration, being more computationally expensive, was only run for 4 time-slices of 1 month each, with initial conditions from UKMO operational analyses.

WRF version 3.1.1 (Skamarock et al., 2008) is a global NWP model. In this study the model configuration has 38 vertical levels, with a terrain-following hydrostatic-pressure vertical coordinate system from surface to $5 \mathrm{hPa}(\sim 37 \mathrm{~km})$. The horizontal resolution is $1.87^{\circ} \times 1.25^{\circ}(\mathrm{N} 96)$. The model initial condition is derived from ECMWF analyses. The surface and boundary layer were represented using the quasinormal scale elimination (QNSE) parameterisation scheme by Sukoriansky et al. (2005). The WRF Single-Moment 
(WSM) 6-class scheme (with graupel) is used for the microphysics parameterisation (Hong and Lim, 2006). Sub-grid scale effects of convective and shallow clouds are parameterised using the Betts-Miller-Janjic (BMJ) cumulus scheme (Janjic, 1994, 2000). The scheme uses an ascending particle that mixes with its environment to determine the convective cloud top height. The work of the buoyancy force on the ascending particle is required to exceed a prescribed positive threshold.

CATT-BRAMS (Freitas et al., 2009) is a non-hydrostastic limited area model. The grid spacing is $0.5^{\circ} \times 0.5^{\circ}$ with 39 vertical levels from surface to $\sim 40 \mathrm{~km}$. Shallow and deep convection are parameterised following the ensemble parameterisation described in Grell and Dévényi (2002). Microphysics at the grid-scale is calculated using a one-moment bulk microphysics parameterization which includes the prediction of the mixing ratios of water vapour, cloud water, rain, pristine ice, snow, aggregates, graupel and hail and the concentration of pristine ice (Walko et al., 1995). Sea surface temperatures are derived from satellite weekly analyses. Initial conditions are from ECMWF analyses and the model is relaxed at the lateral and top boundaries to ECMWF 6hourly analyses. This model configuration was run for 3 separate months and each model integration was centred on one of the three domains under investigation (namely, February 2005 for South America, August 2005 for West Africa and November 2005 for the Maritime Continent).

ERA-Interim (Simmons et al., 2007) is the latest ECMWF reanalysis dataset for the period 1989 to present. In addition to satellite observations, we use this reanalysis data to compare precipitation and water vapour with our set of models. The ERA-Interim reanalyses are produced by the ECMWF IFS model, cycle 31, which has been operational from September 2006 to June 2008. The model resolution is T255 $\left(\sim 0.5^{\circ} \times 0.5^{\circ}\right)$ with 60 vertical levels and model top at $0.1 \mathrm{hPa}(\sim 60 \mathrm{~km})$. The main improvements of ERAInterim with respect to the previous ECMWF reanalysis dataset, ERA-40, include: higher horizontal resolution, 4-DVar data assimilation, new humidity analysis and improved model physics. The archived ERA-Interim data is truncated to $1.5^{\circ}$ and does not include specific information on convective cloud top height (we are therefore not using this variable for comparison with model output).

\section{Observational datasets}

Several satellite products are used to analyse the seasonal variability of deep convection in the tropics and to evaluate model results. Satellite estimates are preferred to other types of data because they provide a global and consistent coverage over the whole simulation period (i.e. the whole 2005 year). The high spatial and temporal coverage also allows us to make statistical comparisons with model results, which can be difficult with more sparse campaign data. The data retrieval from satellite observation is a complex process, leading to uncertainties in the measurements. Since these uncertainties are often hard to quantify, we have used more than one satellite product for each of the meteorological variables under investigation, thus providing an indirect measure of the uncertainty range in the observations.

We use precipitation rates, outgoing longwave radiation (OLR), cloud top pressure (converted to cloud top height), and water vapour at $150 \mathrm{hPa}$, to infer convective activity and analyse the seasonality and preferred locations of tropical convection. We additionally focus on surface precipitation rates and cloud top height to assess how well current models can represent tropical convection characteristics such as spatial patterns and vertical extent. Modelled vertical profiles of water vapour are compared to satellite observations and reanalysis data for a qualitative analysis of vertical transport in the UTLS region. OLR was not used for comparison with model data since this diagnostic is not easily available from CTMs.

\subsection{Surface precipitation rates}

Analysis of surface precipitation rates is performed using monthly mean estimates. Several products based on different satellite data and/or retrieval approaches are available for 2005.

The first product used for our analysis is the Tropical Rainfall Measuring Mission (TRMM) 3A12 dataset. It is available as a monthly mean at $0.5^{\circ} \times 0.5^{\circ}$ resolution calculated from the $2 \mathrm{~A} 12$ dataset. $2 \mathrm{~A} 12$ provides instantaneous rainfall rates and the vertical structure of hydrometeors and latent heating based upon the nine channels of the TRMM microwave imager, TMI (Kummerow et al., 1998). The processing algorithm (Kummerow et al., 1996) is based upon a Bayesian approach that begins by establishing a large database of potential hydrometeor profiles and their computed brightness temperatures. This database is computed from cloud resolving model simulations.

The second product used for this analysis is the Global Precipitation Climatology Project (GPCP) dataset. We use the V1.1 daily mean dataset (1DD) on a $1^{\circ} \times 1^{\circ}$ grid to compile monthly means. This approach is preferred to the use of the monthly mean dataset since the latter is only available on a $2.5^{\circ} \times 2.5^{\circ}$ grid. The $1 \mathrm{DD}$ uses a combination of observational datasets that have desirable time/space coverage (Huffman et al., 2001). The datasets include geosynchronous-orbit infra-red brightness temperatures, low-orbit infra-red Precipitation Index from the Geostationary Operational Environmental Satellite (GOES), TIROS Operational Vertical Sounder (TOVS) and Atmospheric Infrared Sounder (AIRS). Although microwave precipitation estimates and gauge analyses are not explicitly used due to sampling limitations, the calibration of the 1DD to the monthly GPCP product ensures that they do have a strong influence on the overall scaling. 
The third dataset is from the National Oceanic and Atmospheric Administration (NOAA) Climate Prediction Center (CPC) Merged Analysis of Precipitation, CMAP. It uses a technique which produces monthly analyses of global precipitation in which observations from raingauges are merged with precipitation estimates from several satellite-based algorithms (infrared and microwave). It uses values obtained from five kinds of satellite estimates: Global Precipitation Index (GPI), outgoing-longwave radiation precipitation index (OPI), Special Sensor Microwave Imager (SSM/I) scattering, SSM/I emission and Microwave Sounding Unit (MSU). The analyses are on a $2.5^{\circ} \times 2.5^{\circ}$ grid. The merging technique is thoroughly described in Xie and Arkin (1997).

\subsection{Cloud top pressure/height}

For the analysis of Cloud properties we use cloud top pressure from 3 datasets. Since data from more recent instruments, such as CALIPSO and CloudSat, is only available from late 2005-2006, we can not use it directly in this study.

The first dataset is the D1 product from ISSCP (Rossow and Schiffer, 1991; Rossow et al., 1993). Since July 1983, ISCCP has been collecting the infrared and visible radiances obtained from imaging radiometers carried on the international constellation of weather satellites. The analysis is composed of two major procedures: the cloud detection procedure divides the radiances into cloudy and clear groups and the radiative analysis procedure retrieves physical properties of clouds and the surface, respectively. For each individual pixel, either surface properties or cloud properties are retrieved from the pixel radiances depending on whether the threshold tests indicate clear or cloudy conditions. This creates the DX product. The D1 product is produced by combining the pixel-level results (DX data) every $3 \mathrm{~h}$ on an equal area map grid with $280 \mathrm{~km}$ or $\sim 2.5^{\circ}$, resolution and merging the results from separate satellites to produce global coverage at each time. One particular advantage of the ISCCP data is the high temporal resolution which allows sampling of the full diurnal cycle of convection.

The second and third datasets are from the MODerate resolution Imaging Spectroradiometer (MODIS) on board the Terra and Aqua Earth Observing System (EOS) platforms (King et al., 2003). Unlike the ISCCP cloud climatology, the MODIS cloud data is collected from 2 sun-synchronous satellites, which sample cloud properties at 10:30 a.m./p.m. and 01:30 a.m./p.m. local time for EOS-Terra and EOSAqua, respectively. We use the Level-3 aggregated cloud top pressure provided daily on a $1^{\circ}$ equal-angle grid. MODIS uses a $\mathrm{CO}_{2}$ slicing technique (Wylie and Menzel, 1999) to evaluate cloud top pressure from radiances measured in spectral bands located within the broad $15-\mu \mathrm{m} \mathrm{CO}_{2}$ absorption region. One advantage of this measurement technique is that cloud properties are derived similarly for both daytime and nighttime data as the IR method is independent of solar illumination. This approach is also very useful for the detection of mid-level to high-level clouds, and especially semi-transparent clouds such as cirrus (Ackerman et al., 2008). Due to the presence of cirrus clouds, the MODIS data can be considered as an upper limit for observed convective clouds.

Cloud top pressures were converted to cloud top heights using 6-hourly geopotential height from ECMWF analyses (interpolated to 3-hourly for the ISCCP dataset).

\subsection{OLR}

OLR data for the year 2005 is obtained from two datasets. The first dataset is derived from radiances measured by the NOAA polar-orbiting satellites (Gruber and Krueger, 1984). The data, provided by the NOAA/OAR/ESRL PSD, is interpolated in space and time to eliminate missing values; the interpolation technique is described in Liebmann and Smith (1996). We use monthly mean data, which is available globally on a $2.5^{\circ} \times 2.5^{\circ}$ grid. The data is available from the NOAA website at http://www.esrl.noaa.gov/psd/.

The second dataset is from the AIRS instrument onboard EOS-Aqua satellite (Aumann et al., 2003). We use Level 3 Daily standard physical retrievals. AIRS is a high resolution spectrometer with 2378 bands in the thermal infrared and 4 bands in the visible. The OLR data has a global coverage, with a $1^{\circ} \times 1^{\circ}$ grid-spacing. Daily values were averaged to produce monthly means.

\subsection{Water vapour}

Water vapour can be retrieved from different types of instruments but mainly in the troposphere where it is abundant. In the UTLS, because of the large vertical gradient and the very low values, water vapour measurements have large uncertainties.

The first dataset is obtained from the Microwave Limb Sounder (MLS) version 2.2, onboard EOS-Aura satellite (Sun-synchronous). MLS provides water vapour mixing ratios in the upper troposphere and stratosphere. The spatial coverage is $\left(82^{\circ} \mathrm{S}\right.$ to $\left.82^{\circ} \mathrm{N}\right)$, with each profile spaced $1.5^{\circ}$ or $\sim 165 \mathrm{~km}$ along the orbit track (roughly 15 orbits per day). The recommended useful vertical range is between 316 and $0.002 \mathrm{hPa}$, and the vertical resolution is about $1.5 \mathrm{~km}$ at $316 \mathrm{hPa}$ decreasing to $3.5 \mathrm{~km}$ to $4.6 \mathrm{hPa}$. The individual water vapour profiles were averaged on to a $5^{\circ} \times 5^{\circ}$ grid at each pressure level to obtain monthly mean fields.

The second dataset is the Level 3 daily water vapour from the AIRS-Aqua measuring platform (Divakarla et al., 2006). The band ranges of the AIRS instrument have been specifically selected to allow determination of atmospheric humidity with an accuracy of $20 \%$ in layers $2 \mathrm{~km}$ thick in the troposphere (Susskind et al., 2003). The AIRS/Aqua Level 3 Daily data has a global coverage, with a $1^{\circ} \times 1^{\circ}$ grid-spacing, and the useful vertical range for water vapour is $1000-100 \mathrm{hPa}$. Daily values were averaged to produce monthly means. 

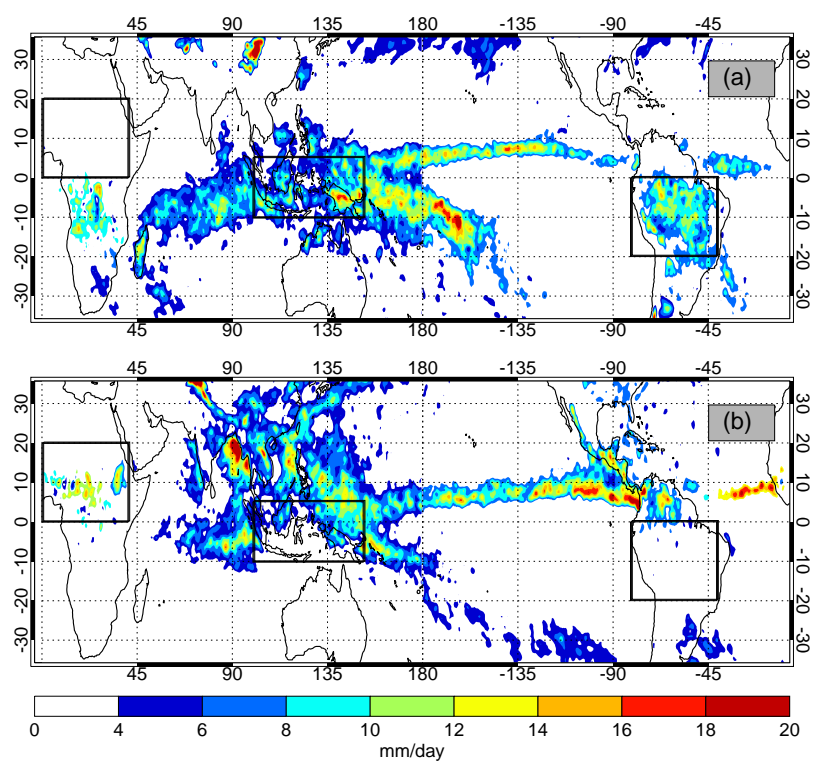

Fig. 1. Mean precipitation rates from TRMM dataset for the year 2005: (a) DJF, (b) JJA. The black boxes identify domains under investigation, namely West Africa $\left(0: 20^{\circ} \mathrm{N} ; 0: 40^{\circ} \mathrm{E}\right)$, the Maritime Continent $\left(10^{\circ} \mathrm{S}: 5^{\circ} \mathrm{N} ; 100: 150^{\circ} \mathrm{E}\right)$, and South America $\left(20: 0^{\circ} \mathrm{S}\right.$; $\left.80: 40^{\circ} \mathrm{W}\right)$.

\section{Results}

The seasonal and regional patterns of convection are illustrated in Fig. 1 for the Southern and Northern Hemisphere summer season. This figure shows convective activity inferred by precipitation rates from the TRMM dataset. Among the areas where convection is strongest are the Maritime Continent in both seasons, South America in DJF and West Africa in JJA (highlighted with black boxes). Strong convection also occurs in other tropical regions, such as Southern Africa and the West Pacific tropical warm pool region (located to the east of Australia and Papua New Guinea). However, we focus our modelling efforts on the three domains shown in Fig. 1, which have been the focus of extensive measurement campaigns aimed at understanding tropical convection, particularly its interactions with aerosols and chemical species, and its impact on transport of pollutants and water vapour to the UTLS (Pommereau et al., 2007; Vaughan et al., 2008; Cairo et al., 2010).

By choosing these three geographical domains, we are comparing areas where tropical convection has very different strength, seasonality and diurnal variation, and is also initiated by different mechanisms. The initial stages of cumulus convection are determined by soil moisture and other surface properties in Africa and South America, see for example Koster et al. (2004) and references therein, while in a coastal and island domain, such as the Maritime Continent, sea breeze convergence is the main driver, with convection occurring preferentially over the hot land during the day and over the mild sea at night (Saito et al., 2001; Neale and Slingo, 2003). Comparison of panels a and b in Fig. 1 highlights the strong seasonality of convection for West Africa and South America, and to a lesser extent for the Maritime Continent region.

\subsection{Seasonal cycle of convection and its regional variations}

The seasonal cycle of convection for the year 2005 is shown in detail in Fig. 2, where we analyse observed monthly mean fields averaged over the three domains of interest. This initial analysis is aimed at understanding how different variables, normally used as proxies for the strength of tropical convection, compare to each other. We then compare the different domains to assess which ones have on average stronger convective activity, and how the strength of convection varies with the season. For this analysis we use convective proxies such as surface precipitation rate (from TRMM, GPCP, CMAP), cloud top height (from MODIS-Terra, MODISAqua and ISCCP) and OLR (from AIRS and NOAA). Additionally, we plot water vapour at $\sim 150 \mathrm{hPa}$ (from AIRS and MLS) to investigate whether a correlation exists between water vapour concentration in the TTL and the strength of the convection. The use of different observational datasets for each of the analysed variables highlights the range of variability in the observations. In order to ascertain that our comparison of the three domains in question is not biased by the use of a single year of data, we also plot mean GPCP surface precipitation rates for the period 1979 to 2000 . The comparison between precipitation rates for 2005 and the 20year mean suggests that the convective behaviour (strength and seasonality) for the three domains in the year 2005 is not atypical.

Differences in the mean strength and seasonality of convection between the different domains are shown in Figure 2. The seasonal cycle of precipitation rates (black lines) is more marked for West Africa and South America, with distinctive maxima and minima, and less so for the Maritime Continent domain. The lack of a marked minimum in the seasonal cycle for the Maritime Continent, compared to the other regions, is partly explained by the latitudinal range chosen for this domain (which lies more symmetrically across the Equator) and partly by differences in convective forcing. While convection in West Africa and South America is modulated by large scale circulation processes with marked seasonal cycle (e.g. monsoons), convection occurring over the warm oceans and islands in the Tropics can be additionally driven by local processes (e.g. sea breezes) which are mostly influenced by the diurnal cycle. As a result, the tropical oceanic region between $90^{\circ}-180^{\circ}$ longitude receives a significant amount of rainfall throughout the year (as can be seen in Fig. 1).

Figure 2 shows that the difference in precipitation rates between the three observational datasets (TRMM, GPCP and CMAP) is generally small for Africa and South America, 
with differences of about $15 \%$ and 5\% respectively, consistent with previous studies (Adler et al., 2009). For the Maritime Continent however, differences are on average around $30 \%$. The differences between the datasets suggests that precipitation rates in the Maritime Continent region are not so well constrained, possibly due to higher uncertainties on the precipitation estimates over ocean regions (Bowman, 2005; Adler et al., 2009). We will extend our discussion on precipitation in Sect. 4.2.

While precipitation rates show the convective signal at the surface, OLR shows the convective signal at the top of the atmosphere. OLR is a complex variable and its value depends on the height of clouds, as well as temperature and water vapour concentrations at the convective outflow level. Despite its complexity, the seasonal cycle of OLR (green lines) mirrors closely that of precipitation, with minimum values where precipitation, and therefore convection, is highest and vice-versa. The two OLR datasets are in good agreement, except for a constant bias of around $10 \%$.

The mean cloud top heights are derived from daily (MODIS-terra, red lines) and 3-hourly (ISCCP, red diamonds) data, using only gridpoints where the time-resolved cloud top is greater than zero (i.e. gridboxes which show no clouds in the daily/3-hourly data are not used in the averaging). The two MODIS datasets are generally in good agreement, with differences of 5-10\%. Studies by Liao et al. (1995a, b) show that ISCCP tends to underestimate the height of clouds with diffuse tops, particularly frequent in the Tropics, and it also underestimates the fraction of high clouds since it fails to capture high level clouds with low optical thicknesses. Despite its inability to detect cirrus clouds, the monthly mean ISCCP cloud top heights generally show good agreement with MODIS for the domains under investigations. One instance in which ISCCP shows a negative bias with respect to MODIS is for the Maritime Continent in November, suggesting that large fractions of cirrus clouds are present for this region and period, which are reflected in higher MODIS cloud tops. The seasonal cycle of cloud top heights follows that of precipitation for the Maritime Continent and South America. However, it shows high values for West Africa throughout the year. Since precipitation rates are low and OLR values are high in the November to March period compared to August, we conclude that the high cloud top values observed for West Africa in this period could be due to problems in the attribution of cloudy pixels over desert areas of Africa; this is supported by the geographical distribution of monthly mean cloud top pressures, which show anomalously low values (high clouds) throughout the year for the Sahara desert, Greenland and Antarctica, which have higher than average surface albedos.

The analysis of convective activity for each of the domains in the year 2005, suggests that the relative strength of convection is greater for the Maritime Continent compared to the other tropical regions. However, this analysis shows a monthly mean picture of convective properties averaged over
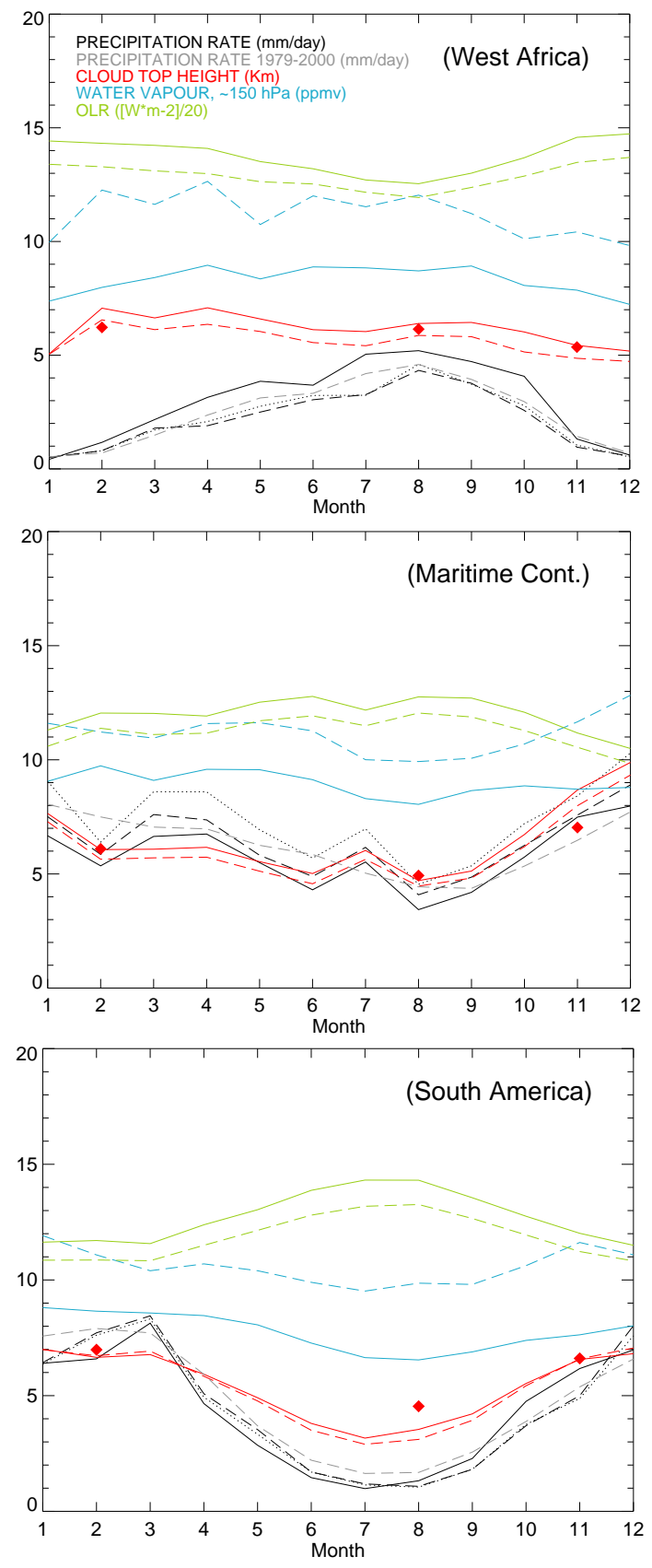

Fig. 2. Seasonal cycle of convection for 2005 averaged over West Africa, Maritime Continent, South America. Precipitation rates in black from TRMM (solid line), GPCP (dashed line), CMAP (dotted line); cloud top heights in red from MODIS-terra (solid line), MODIS aqua (dashed line) and ISCCP (diamonds); OLR in green from AIRS (solid line) and NOAA (dashed line); water vapour in light blue from AIRS at $150 \mathrm{hPa}$ (solid line) and AURA-MLS at $147 \mathrm{hPa}$ (dashed line). Additionally, the grey curve shows the seasonal cycle of precipitation rates in $\mathrm{mm}$ /day for the GPCP long-term climatology (1979-2000). 
a large domain and does not give an estimate of the relative strength and frequency of single convective events. The analysis in Sect. 4.3 will address this point by using highly temporally-resolved data and focusing on the month with the highest convective activity for each domain.

We now focus on the analysis of water vapour mixing ratio at $150 \mathrm{hPa}(14-15 \mathrm{~km})$. Water vapour can be considered as a tropospherically abundant tracer, with a marked vertical gradient and very small values in the UTLS; temperature-driven phase transitions and removal through precipitating clouds however, make water vapour a complex tracer to assess convective transport. The correlation of upper tropospheric humidity and deep convection has been previously investigated by Liu (2007) using MLS data and by Savtchenko (2009) using AIRS data. In this study, both water vapour datasets are correlated to convective proxies from several satellite observations. The seasonal cycle from AIRS and MLS water vapour observations is shown in Fig. 2. The two water vapour products show similar variations but a nearly constant bias of about $30 \%$ for all considered regions. This bias is consistent with MLS validation studies by Read et al. (2007) and Lambert et al. (2007) based on comparisons with different datasets, including AIRS. Because of this relatively large bias, we focus on the relative variations of water vapour with the season, rather than on the absolute concentrations. Firstly we analyse how the seasonal variation of the two water vapour datasets compare with each other: correlation of AIRS and MLS seasonal cycles is relatively high for West Africa and South America, where they correlate with a coefficient of 0.76 and 0.72 , respectively; for the Maritime Continent, the seasonal variation of the two water vapour datasets shows larger differences, with a correlation coefficient of 0.52 . Secondly we analyse how the seasonal variation for each of the water vapour datasets correlates with the seasonal variation of convection, as inferred by the different convective proxies. For South America both water vapour datasets suggest that the seasonal variation of water vapour mixing ratio at $150 \mathrm{hPa}$ is modulated by the strength of convection (with a mean correlation coefficient of 0.83 ); for West Africa and the Maritime Continent the different water vapour datasets disagree on the extent of the correlation, producing a mean correlation coefficients of 0.64 and 0.43 respectively. Although this analysis suggests that convection can, in some regions, modulate water vapour concentrations up to $150 \mathrm{hPa}$, further studies including several years of data and additional information on temperature, are necessary to understand the role of convection in moistening the TTL, and to assess whether the correlation we observe between convection and water vapour concentrations at $150 \mathrm{hPa}$ is due to direct vertical transport by convection or to indirect effects of convection on the vertical temperature profile.

In Fig. 3 we compare the observed seasonal cycle of surface precipitation rates with model data to assess the models' ability to reproduce the observed seasonal variations for the different regions. For West Africa and South America all
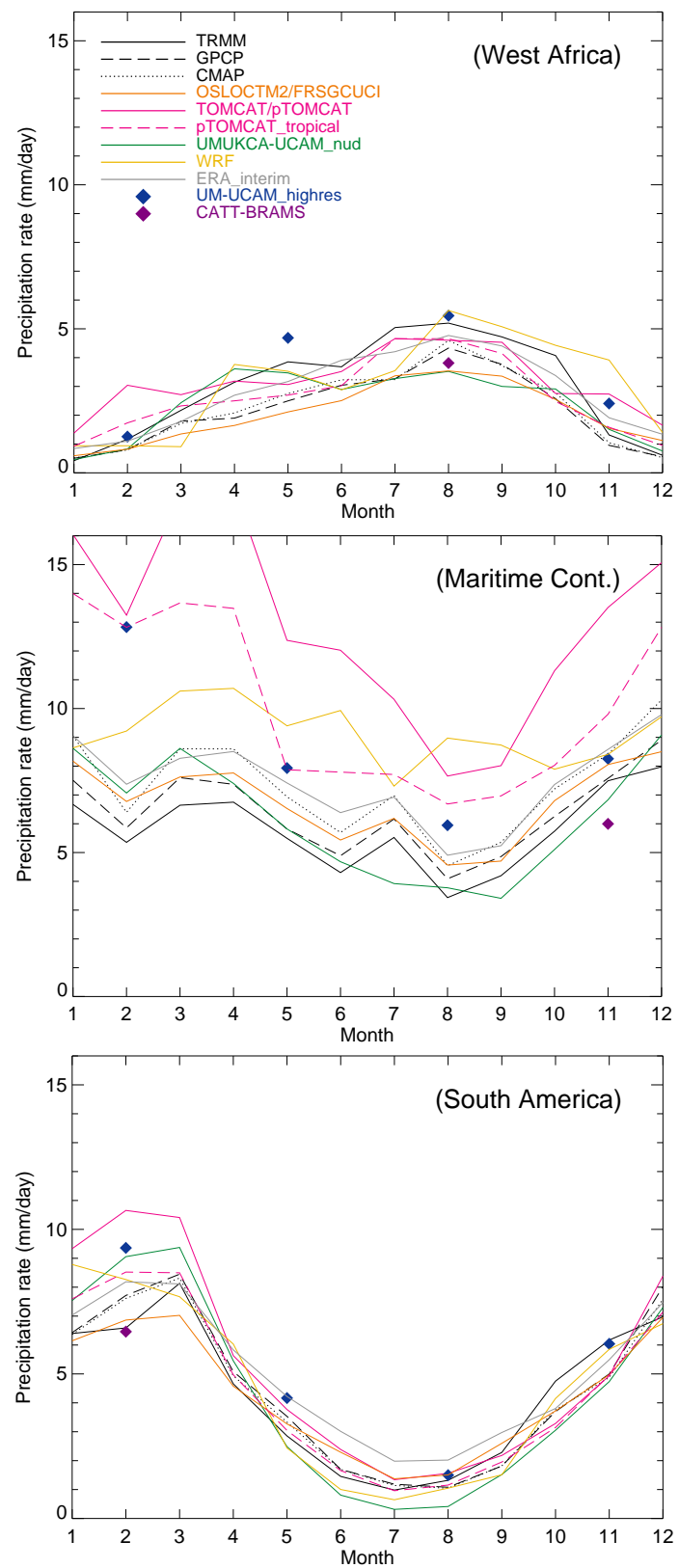

Fig. 3. Seasonal cycle of surface precipitation rate for the year 2005 from observations (TRMM, GPCP and CMAP) and model simulations, averaged over West Africa, the Maritime Continent and South America.

models can represent reasonably well the average strength and seasonality of convection (inferred from surface precipitation). For these two regions the models' precipitation rates are mostly within the range provided by the observational data. However, the spread of model data is much larger for the Maritime Continent region, with some models greatly overestimating surface precipitation and others somewhat underestimating it. These results indicate that the set of 
models used in the current study generally tends to better simulate continental precipitation and their well marked dry and wet season. In the next section we concentrate on these large model differences for the Maritime Continent region and try to understand their origin.

\subsection{Assessment of model geographical distribution of convection}

A better understanding of the models' discrepancies with observations in the Maritime Continent can be gained in this section by analysis of the geographical distribution of convection. We start by investigating the annual mean geographical distribution of surface precipitation rates for the year 2005, shown in Fig. 4. Most of the models represent the geographical distribution of surface precipitation reasonably well. Observed precipitation rates show a large annual signal for the Indian Ocean, the Maritime Continent, the Inter Tropical Convergence Zone (ITCZ), the South Pacific Convergence Zone (SPCZ) and South America, and a smaller signal for Central Africa. A few of the models tend to slightly overestimate the precipitation rates in the West Pacific. TOMCAT-based models overestimate precipitation rates over large regions in the Tropics, particularly over the oceans; this is possibly due to the model's simplified method for calculating heat and moisture fluxes at the surface, which are then used to initiate convection. Convective events in these models are therefore more widespread and frequent over the ocean, producing large areas where mean precipitation rates are higher than observed.

Figures 5, 6 and 7 show a more detailed analysis of precipitation rates for each of the three domains in the months of their maximum convective activity. Since the largest differences between observed and modelled precipitation rates occur in the Maritime Continent region (see Fig. 3 and 4), we will focus on the detailed analysis of convection in this area for the month of November. Figures 6 and 8 show a comparison between observed and modelled precipitation rates and cloud top heights, for November 2005 . The observed surface precipitation rates show higher values over the large islands, in particular over the high orography of Borneo and New Guinea, and the Malaysian Peninsula; the precipitation enhancement over land is greatest in the TRMM data compared to the other datasets, and this is likely to be due to its higher resolution $\left(0.5^{\circ} \times 0.5^{\circ}\right)$ which enables it to resolve smaller scale features. All the observed precipitation maps also show increased precipitation over some specific ocean areas, in particular south-west of Sumatra and north of New Guinea. In comparing modelled precipitation with observations, one should bear in mind that most of the models used in this paper have a low resolution which is similar to that of the CMAP dataset; one exception is WRF, with a resolution closer to that of GPCP data, while UM-UCAM highres and CATT-BRAMS have a resolution similar to TRMM data; we can therefore compare each model to the dataset having comparable resolution.

For the comparison of observed and modelled precipitation rates, we focus on the geographical patterns of precipitation rather than the actual precipitation values, since some models have biases in the mean precipitation rates, as shown in Fig. 3. Most of the coarse resolution models have a poor representation of the precipitation maxima over land areas. At a coarse resolution, similar to that used by most of the models in this study, the land-sea contrast in temperature and moisture, and surface characteristic such as coastlines and orography, are not well defined; consequently the formation of moisture rich sea-breezes, their inflow over the islands, and their interaction with orography, leading to enhanced precipitation, are not particularly well represented. This could explain the general lack of precipitation maxima in Borneo, New Guinea and the Malaysian peninsula region for most of the coarse resolution models. With an intermediate resolution, WRF shows some local precipitation maxima over land areas. UM-UCAM highres, CATT-BRAMS and, to a lesser extent, ERA-Interim show a precipitation enhancement over land in agreement with observations. Comparison of observed and modelled precipitation rates over ocean areas show that the TOMCAT-based models tend to overestimate precipitation intensities (as discussed earlier), WRF also shows a large precipitation maximum in the oceanic region north of New Guinea, while CATT-BRAMS generally underestimates precipitation rates over ocean areas. This seems to suggest that a higher model resolution does not necessarily result in an improvement on the location of oceanic precipitation.

In summary, models with a coarse horizontal resolution generally fail to correctly represent the enhanced precipitation rates over the islands and peninsulas of the Maritime Continents; differences between observed and modelled precipitation rates over the ocean seem to be less sensitive to horizontal resolution and are harder to attribute, being affected by a combination of factors, such as regional circulation patterns, moisture fluxes at the sea surface and microphysical parameterisation, which are represented differently in the different models. The difficulty for the current set of models to correctly represent the location and intensity of precipitation maxima over island and peninsulas, and the correct precipitation over oceanic regions, results in the Maritime Continent region showing large biases with respect to observations.

To complement the information on the geographical distribution of convection inferred from precipitation rates, the distribution of mean cloud top heights for November 2005 is illustrated in Fig. 8. The large bias between ISCCP and MODIS cloud top heights can be attributed to the different methods used to detect clouds: while the MODIS instrument is able to view the thin, persistent cirrus clouds (Wylie and Menzel, 1999) which are likely to originate at the convective outflow level, ISCCP estimates the properties of the 

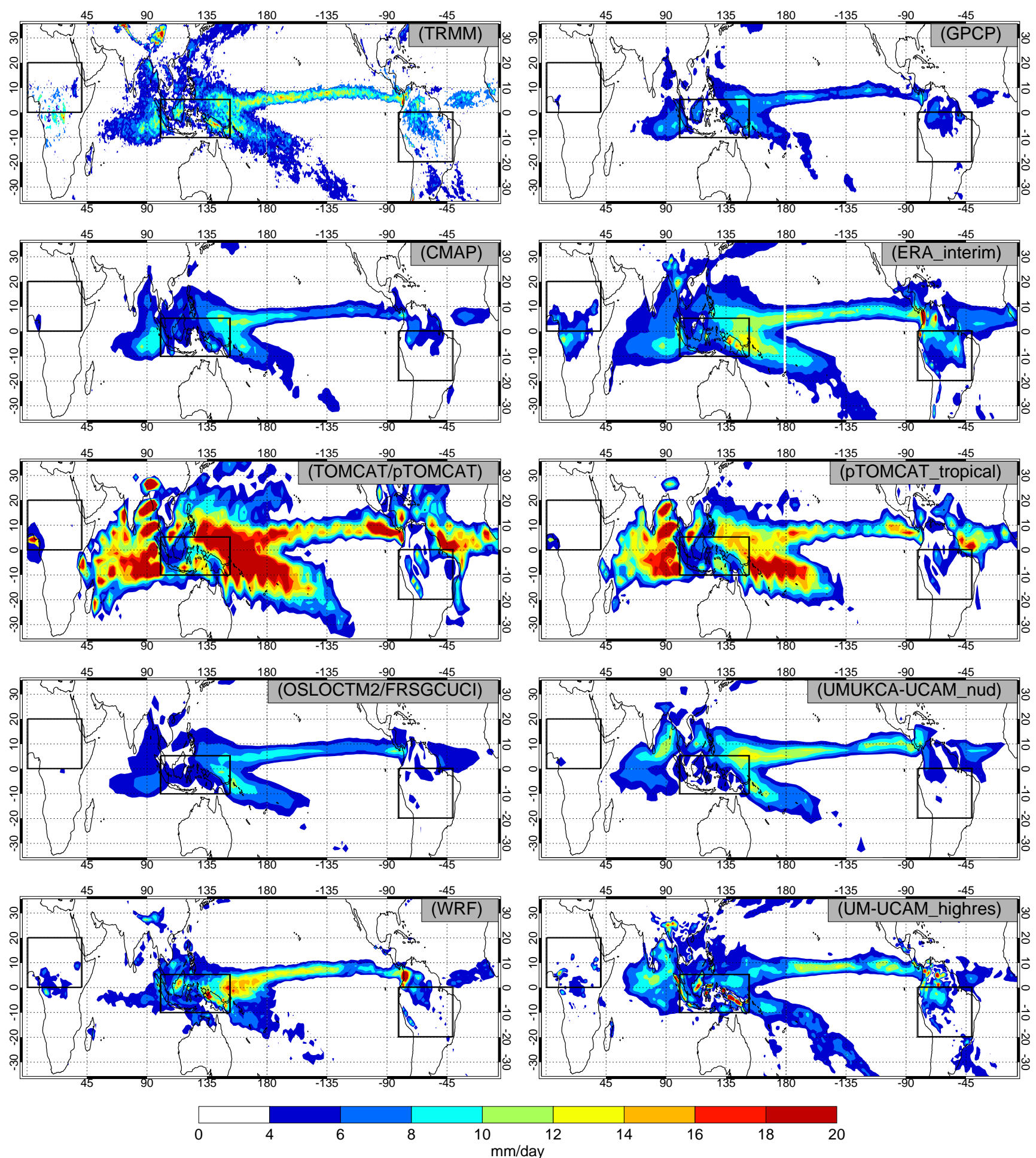

Fig. 4. Annual mean precipitation rates for the year 2005: observations (TRMM, GPCP and CMAP), reanalysis data (ERA_interim) and model simulations. Note that for UM-UCAM_highres the plot shows an average for the months of Febuary, May, August and November.

radiatively effective cloud top. This can explain why the two MODIS datasets have consistently higher mean cloud tops compared to ISCCP. The time sampling of the 3 datasets is also different; the monthly mean cloud heights are calculated from 3-hourly values for ISCCP, and from daily values for the two MODIS datasets, sampled respectively at 

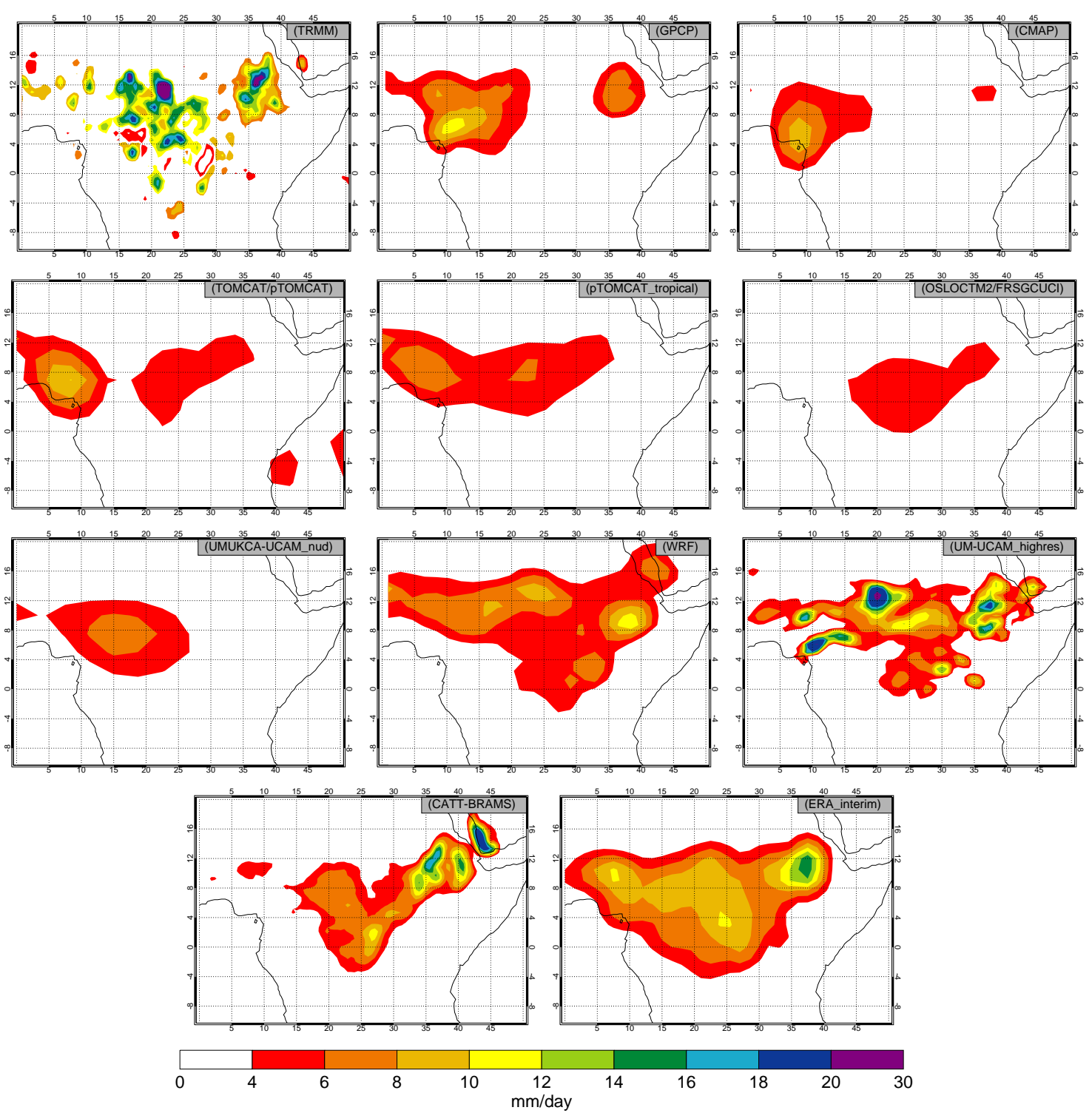

Fig. 5. Monthly mean precipitation rates in West Africa for August 2005: observations (TRMM, GPCP and CMAP), reanalysis data (ERA_interim) and model simulations.

10:30 a.m./p.m. and 01:30 a.m./p.m. for MODIS-terra and MODIS-aqua. However, sub-sampling ISCCP cloud top data at similar times to the two MODIS datasets, showed just small differences in the vertical distribution of clouds (not shown here), with generally smaller fractions of high clouds when ISCCP data is sampled at similar times to MODISaqua, or MODIS-terra. Despite the constant bias, the geographical distribution of convection (inferred from observed mean cloud top height) is very similar in the three observational datasets: mean cloud top heights are generally higher over land than over the sea, with maxima over the Malaysian peninsula, Sumatra, Borneo and New Guinea.
When comparing modelled cloud top heights to the observations the main focus is on assessing the models' ability to represent local maxima and minima rather than the mean value of cloud top height; a more detailed comparison of modelled and observed vertical distribution of clouds is given in the next section. Although the coarse resolution models in this study failed to represent the maxima in precipitation associated with the Malaysian peninsula and Borneo, the maxima in cloud top height over the same areas are reasonably well reproduced by most models. One possible explanation for the unexpected ability of coarse resolution models to represent the maxima in cloud top height over the relatively large region covering the Malaysian peninsula, Sumatra and 

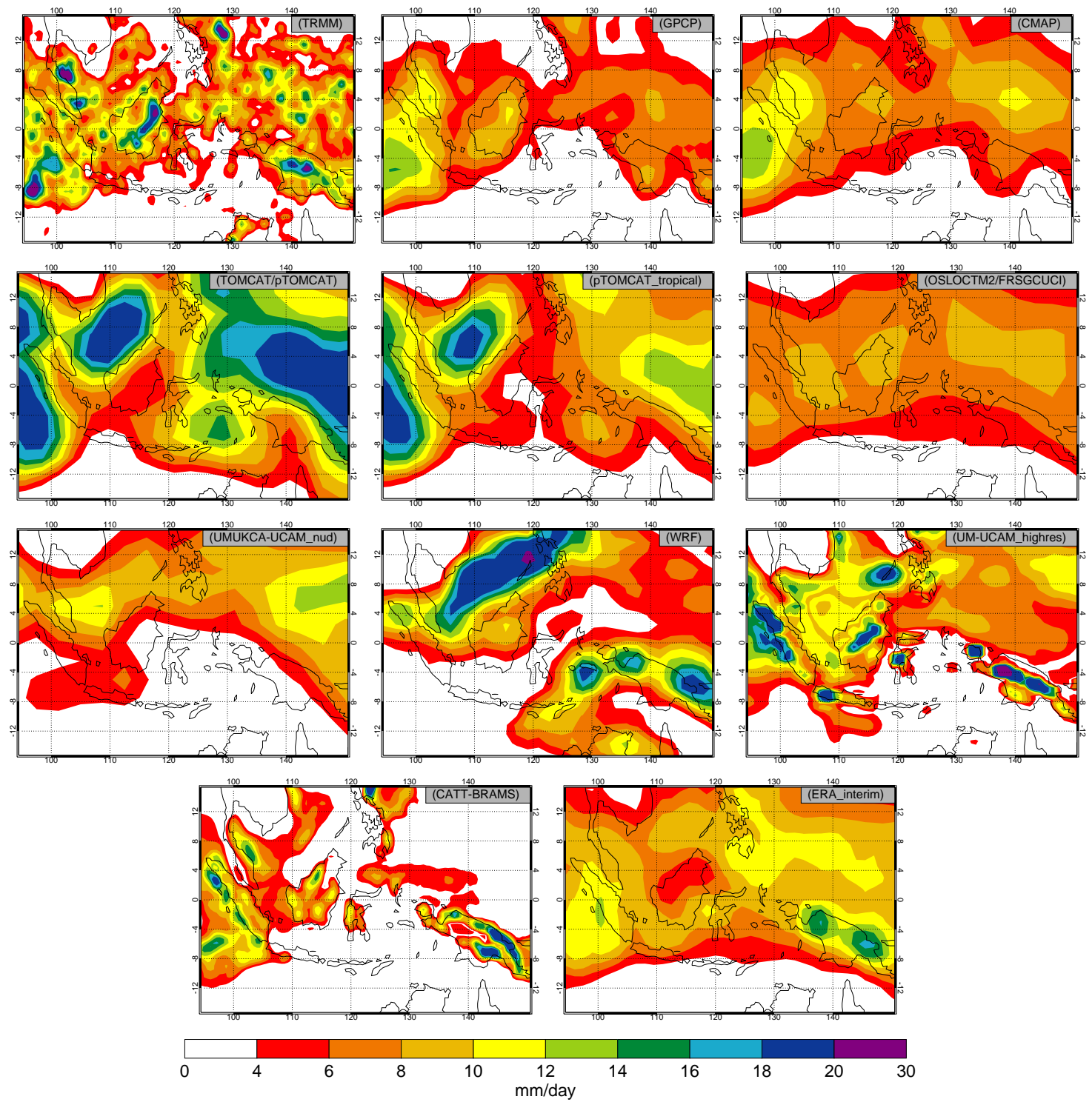

Fig. 6. Monthly mean precipitation rates in the Maritime continent for November 2005: observations (TRMM, GPCP and CMAP), reanalysis data (ERA_interim) and model simulations.

Borneo, while failing to capture the precipitation maxima in the same region is as follows: the coarse resolution models in this study are either CTMs using forcing from ECMWF analyses, or a nudged CCM using the same analyses to constrain its dynamical evolution; the height reached by convective clouds is less sensitive to the model's representation of surface features (such as coastlines and orography) compared to precipitation, and it is more sensitive to mid-level circulation and the vertical structure of the atmosphere, which are constrained to ECMWF analyses. The WRF and UMUCAM_highres models also show different locations for the maxima in precipitation and cloud top height, with both models showing a preference for high clouds over ocean areas which is not mirrored in the observations. CATT-BRAMS shows a consistent picture with marked maxima over land areas. The discrepancy between mean cloud top height and precipitation fields for some of the models suggests that regions of high clouds and high precipitation rates are not always co-located. This is partly due to persistent shallow convection producing maxima in precipitation and not cloud height, and partly to the complex coupling of the deep convection parameterisation and cloud microphysical processes, which might not be adequately represented. Most of the models tend to show higher mean cloud top values compared to observations. This positive bias can be attributed to models generally underestimating fractions of mid-level 

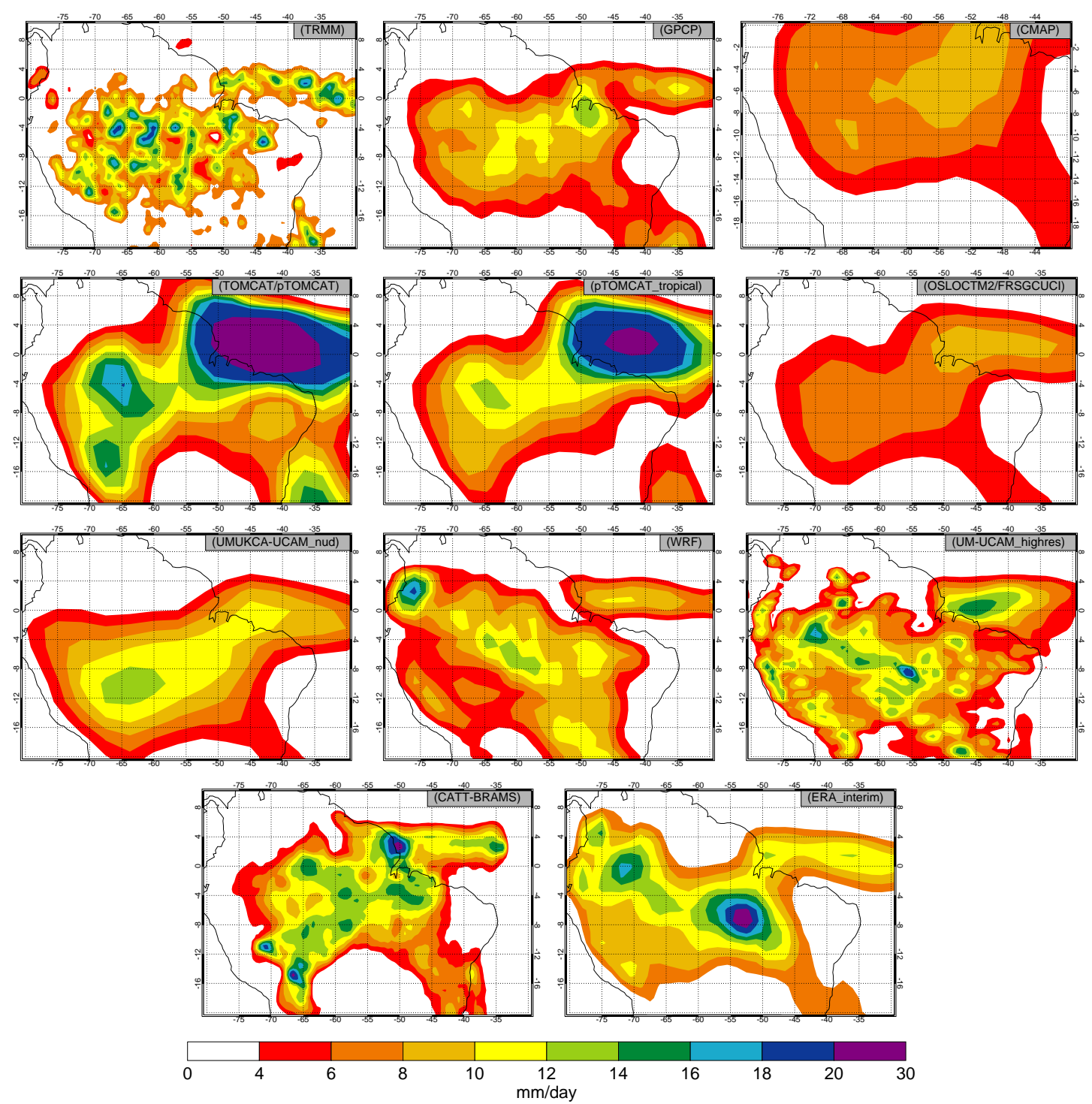

Fig. 7. Monthly mean precipitation rates in South America for February 2005: observations (TRMM, GPCP and CMAP), reanalysis data (ERA_interim) and model simulations.

clouds while overestimating fractions of high-level clouds (Illingworth et al., 2007). This, in turn, has been attributed to convection parameterisation schemes detraining too little moisture at mid levels and consequently detraining too much moisture at high levels. The widespread positive biases for the WRF model can be further explained by the underestimation of shallow convection in this region, which therefore pushes mean cloud top height values upwards. This is further supported by the short-lived (lifetime $\sim 6 \mathrm{~h}$ ) tracer profiles averaged over the Maritime Continent region (Hoyle et al., 2010) which show that all other models have secondary peaks around $600-700 \mathrm{hPa}$ associated with transport by shallow convection, while there is no such peak for the WRF model.
In summary, for the models under investigation, the maxima in precipitation and cloud top height for the Maritime Continent region are not always co-located: coarse resolution models succeed in reproducing the maxima in cloud top height over the Malaysian peninsula, Sumatra and Borneo region but fail to reproduce the maxima in precipitation over the same region; over New Guinea, coarse resolution models fail to reproduce both maxima. Model biases in the mean value of cloud top heights are due to the overestimate of high clouds compared to mid-level and/or shallow clouds.

\subsection{Assessment of model vertical distribution of clouds}

We now attempt to evaluate the ability of models to reproduce the observed vertical distribution of clouds in the three 

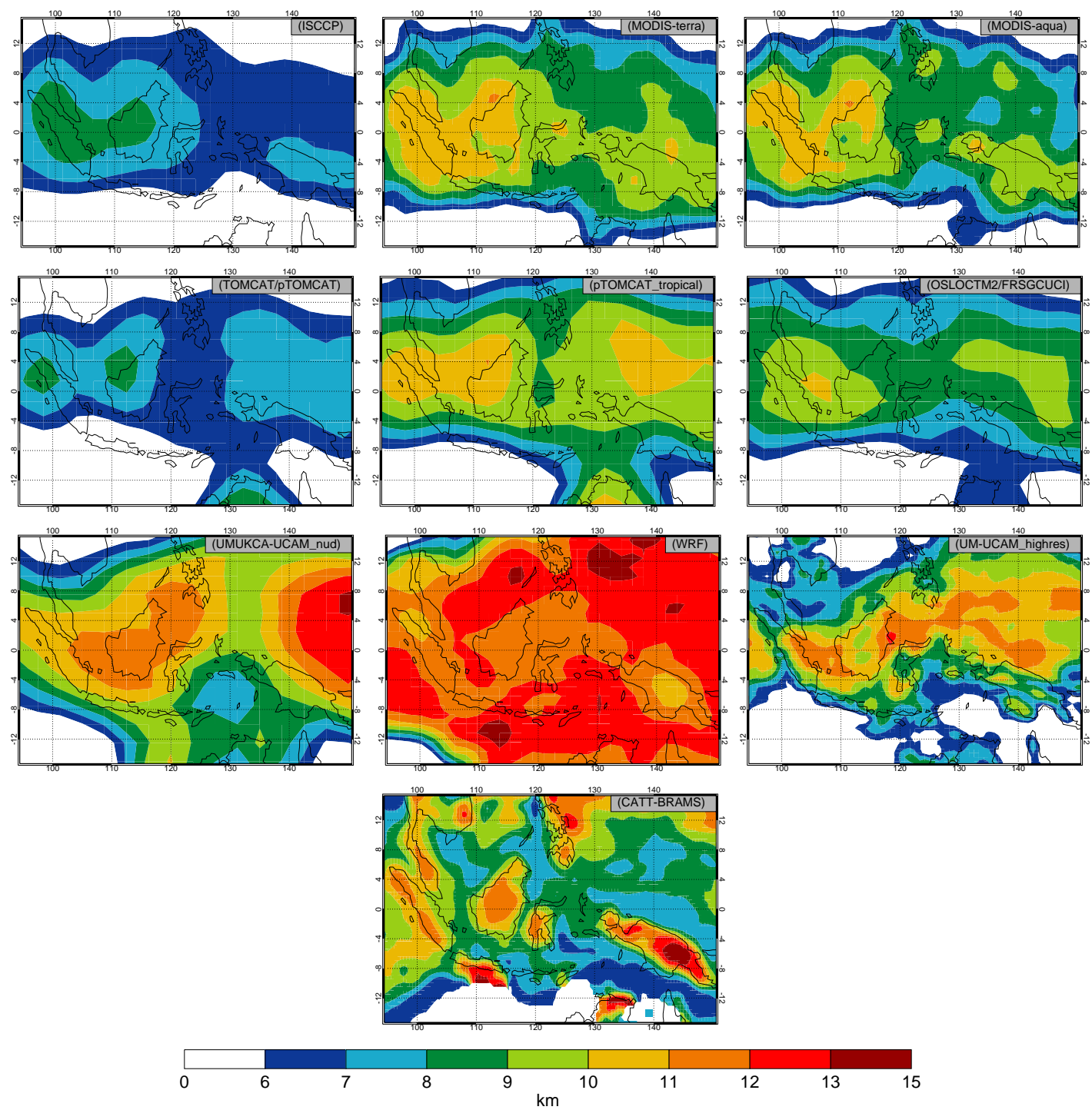

Fig. 8. Monthly mean cloud top height in the Maritime continent region for November 2005: observations (ISCCP, MODIS-terra, MODISaqua) and model simulations. The monthly mean values are calculated from 3-hourly data except for the two MODIS datasets, for which only daily values are available.

highly convective regions of West Africa, the Maritime Continent and South America. For each of the domains we use 3-hourly data (daily for MODIS) to calculate the percentage of grid points, sampled over the domain and over one month, with cloud tops above a certain height. We show the results for clouds above $9-10 \mathrm{~km}$ and we focus specifically on clouds reaching the $Q=0$ level, which is estimated to be $\sim 15 \mathrm{~km}$ (McFarlane et al., 2007). Clouds reaching the $Q=0$ level can detrain surface species which can subsequently be transported upwards at an estimated rate of $0.1-$ $0.2 \mathrm{~K} /$ day (Gettelmann et al., 2004) equivalent to $\sim 0.15-$ $0.30 \mathrm{~km} /$ month. The fraction of clouds reaching this level should therefore give an indication of the relative impact of convection on the composition of the UTLS.
Analysis of Fig. 9 shows that ISCCP generally tends to underestimate mid- and high-level clouds compared to the MODIS datasets. The discrepancy is larger for the Maritime Continent region in November, which is due to the larger fraction of cirrus clouds in this region compared to the other two (Liu, 2007). The detection of cirrus clouds by the MODIS instrument and its implications have already been introduced in Sect. 3, 4.1 and 4.2; for the current analysis of modelled vertical distribution of clouds, the reader is reminded that most of the modelled cloud top heights are derived from the convective parameterisation schemes and therefore do not include cirrus clouds. The MODIS data should therefore be considered as an upper limit for modelled cloud top heights. 

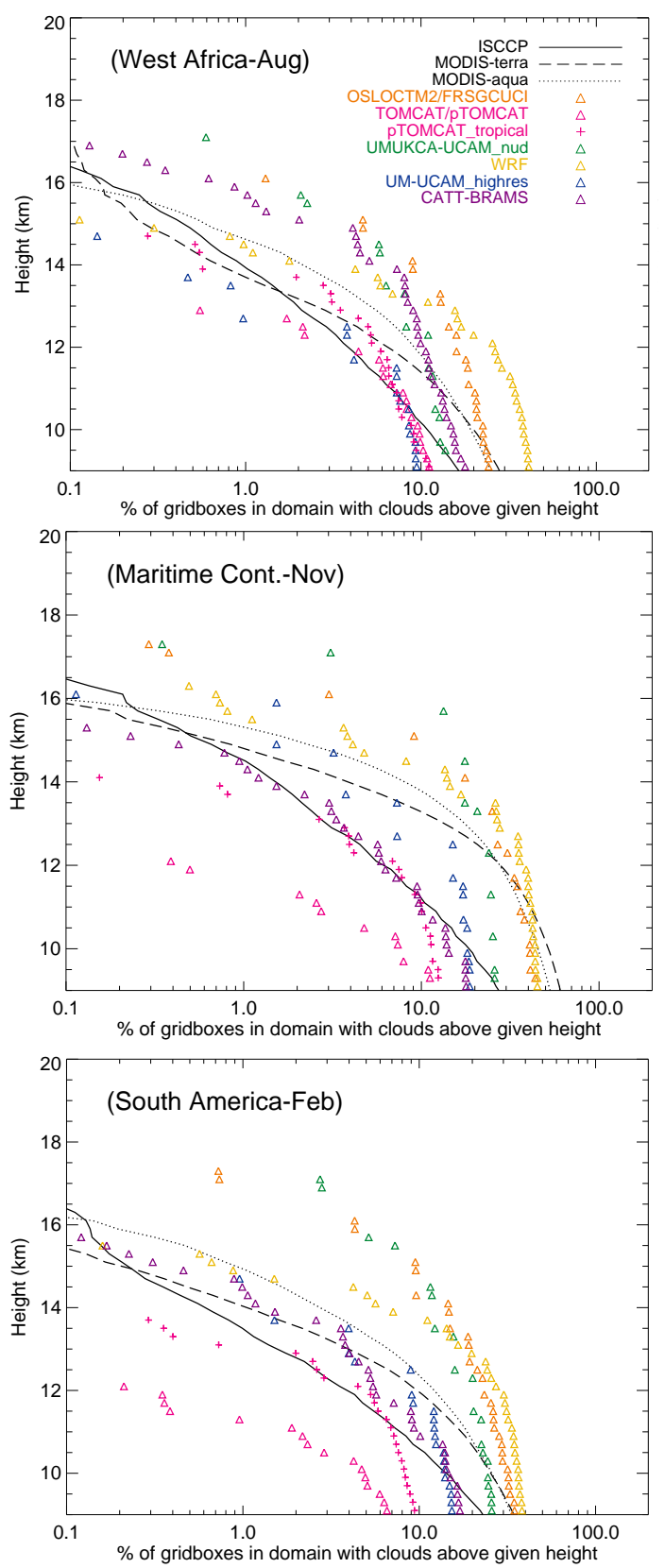

Fig. 9. Percentage of gridboxes in each domain with cloud top above given height from observations (ISCCP, MODIS-terra, MODIS-aqua) and model simulations, calculated for West Africa in August, the Maritime Continent in November and South America in February. The statistical distribution of cloud top heights within each domain is calculated from 3-hourly data, with the exception of MODIS -terra and -aqua for which only daily values are available.

The fraction of observed clouds with tops above $15 \mathrm{~km}$ is in the range $0.5-1.7 \%$ for the Maritime Continent, compared to $0.3-0.6 \%$ for West Africa and $0.2-0.9 \%$ for South America. The corresponding value for a non convective region of the Atlantic ocean (namely [10 S:10 N; 40:0 W]) over a period of three months (February, August and November) is $0.1-0.2 \%$. This suggests that, for the months under investigation, a significantly larger fraction of clouds reaches the $Q=0$ level in the Maritime Continent, West Africa and South America, compared to a non-convective region in the Tropics. Additionally, the analysis of the seasonal cycle of convection in Fig. 2 shows that mean cloud top heights are generally high throughout the whole year for the Maritime Continent region, we can therefore infer that fast vertical transport of surface species to the $Q=0$ level will be more frequent and have a higher impact annually over the Maritime continent region compared to other regions.

Direct injection by overshooting convection is shown to be rare, at least according to this set of observations; the fraction of gridboxes having clouds above $16 \mathrm{~km}$ is at most $0.2 \%$ and often lower than $0.1 \%$ (depending on dataset and region). The percentage of clouds reaching above $16 \mathrm{~km}$ is very similar for the three domains, indicating that there is not a strong regional preference for convection reaching above $16 \mathrm{~km}$. Several short-lived halocarbons, such as bromoform, dibromomethane and methyl iodide, are produced over oceanic regions. These substances and their decomposition products have the potential to destroy ozone very efficiently even at low concentration if they reach the lower stratosphere (Dessens et al., 2009, Hossaini et al., 2010). Quack and Wallace (2003) found that bromoform is produced preferentially in tropical coastal areas and shallow oceanic regions, such as the Maritime Continent. Fast convective transport to the $Q=0$ level (which is $\sim 10$ times more frequent compared to direct injection above $16 \mathrm{~km}$ ), followed by slow radiative ascent, can therefore provide an alternative pathway for short-lived halogenated species of surface origin into the tropical lower stratosphere. The lifetime of water-soluble species produced by oxidation of short-lived halocarbons can in fact be extended above the $Q=0$ level thanks to low water vapour mixing ratios and reduced loss by wet-deposition. This transport pathway could help to explain the discrepancy between the observed and modelled bromine mixing ratio in the tropical stratosphere (Salawitch et al., 2005, WMO Ozone Assessment Report, 2007).

Due to the use of different convection parameterisation schemes, cloud top heights from different models are not always directly comparable, since they are estimated from different model diagnostics (such as convective mass-flux, level of neutral buoyancy, etc.). Additionally, models can have different approaches to simulate the vertical transport by convection, and they differ for example in the values and height chosen for entrainment/detrainment. Therefore the vertical extent of convective transport is not always directly related to the vertical distribution of clouds. Nevertheless, the analysis presented in this section provides a first-order comparison with observations and can additionally be used to interpret the differences in modelled convective transport (Hoyle et al., 2010). The vertical distribution of mid- and high- 
level clouds in this set of models shows a wide range of values: TOMCAT/pTOMCAT underestimate the percentage of gridboxes with clouds tops above $12 \mathrm{~km}$ (or $13 \mathrm{~km}$ for West Africa), OSLOCTM2/FRSGCUCI, UMUKCA_UCAM_nud and, to a smaller extent, WRF tend to overestimate the percentage of gridboxes having clouds with tops above 13$14 \mathrm{~km}$, while pTOMCAT_tropical, UM_UCAM_highres and CATT-BRAMS show cloud heights which are either slightly lower, or within the observed range, depending on the region. Although the vertical distribution of clouds for the higher resolution models is generally closer to the observed range, horizontal resolution is not a major factor in determining the vertical distribution of clouds: in fact pTOMCAT_tropical has a cloud distribution which is closer to observations compared to TOMCAT/pTOMCAT, despite having the same horizontal resolution and the same dynamical fields driving the large scale flow. A more detailed analysis of convection parameterisation in the TOMCAT-based models can be found in Feng et al. (2010). We now assess the ability of models to reproduce the relative strength of convection in the Maritime Continent compared to West Africa: OSLOCTM2/FRSGCUCI, UMUKCA_UCAM_nud, WRF and UM_UCAM_highres all show generally larger fractions of high-level clouds for the Maritime Continent compared to West Africa, which is consistent with observations; all the TOMCAT-based models however, show larger fractions of high clouds for West Africa compared to the Maritime Continent.

In summary, there are generally large differences between the vertical distributions of clouds for the three observational datasets, this is partly due to ISCCP underestimating the fraction and height of high-level clouds, and is particularly obvious for the Maritime Continent region. Nevertheless, some models (e.g. TOMCAT/pTOMCAT) have significant negative biases compared to observations, and others (e.g. OSLOCTM2/FRSGCUCI, and UMUKCA_UCAM_nud) have large positive biases. Analysis of the modelled vertical convective transport of tracers (Hoyle et al., 2010) shows that TOMCAT/pTOMCAT have significantly lower convective outflows compared to other models, which is consistent with the lower cloud top heights compared to observations. Differences in the height of convective outflow between the other models however are small and they do not always reflect directly the modelled vertical distribution of cloud top heights.

\subsection{Assessment of model vertical distribution of water vapour}

Water vapour concentrations in the UTLS are controlled by both temperature and vertical transport. To retain this feature in CTMs, we use an idealized water vapour tracer, since the water vapour field that CTMs read from the analyses is not necessarily subject to the CTM's convective transport. This idealized water vapour tracer is initialised to climatological values and constrained to the same values below $7 \mathrm{~km}$ for the duration of the simulation. Above $7 \mathrm{~km}$ the tracer is subject to transport (including convective transport) and is removed where its concentration reaches the saturation mixing ratio with respect to ice (liquid droplet formation is considered to be negligible above $7 \mathrm{~km}$ ). Unfortunately, the idealised water vapour field was not available for pTOMCAT_tropical.

Figure 10 shows a comparison of observed and modelled profiles of water vapour mixing ratio in the UTLS. Corresponding temperature profiles are shown to help interpretation of the water vapour distributions. For example, the consistently higher water vapour values for West Africa, compared to the other regions, can be explained by higher UTLS temperatures in this region and most models seem to capure this feature reasonably well. However, differences between the observed (including reanalyses) and modelled water vapour vertical profiles in the three regions are generally large, with ERA-Interim showing higher values compared to AIRS and AURA-MLS. The higher water vapour concentrations for CATT-BRAMS and WRF can be explained by the higher temperatures exhibited by these models. OSLOCTM2/FRSGCUCI however, has a very similar temperature profile to TOMCAT/pTOMCAT, therefore its consistently higher water vapour concentrations are due to more efficient vertical transport in OSLOCTM2/FRSGCUCI compared to TOMCAT/pTOMCAT. This is consistent with the vertical distribution of clouds in the two models, shown in Fig. 9, and the vertical distribution of short lived tracers, shown in Hoyle et al. (2010). UMUKCA-UCAM_nud and UM-UCAM_highres generally show low temperatures and corresponding low water vapour concentrations.

\section{Conclusions}

We have analysed the seasonal cycle of convection for three tropical regions (namely West Africa, the Maritime Continent and South America) using a large number of observational datasets for the year 2005. The Maritime Continent shows consistently strong convection throughout the year and the information from monthly mean observations suggests that it has stronger convection compared to the other two regions. Models can reproduce reasonably well the seasonal cycle and observed values of precipitation rates for West Africa and South America, but generally fail to correctly represent monthly mean precipitation rates and their temporal evolution for the Maritime Continent region.

Analysis of the annual mean global maps of precipitation rates also show that models are in better agreement with observations over continental-scale land regions but show larger discrepancies over the islands, peninsulas and ocean regions of the Maritime Continent. Further analysis of the geographical distribution of convection for the Maritime Continent in November, shows that the observed preference for convection over land areas compared to ocean 

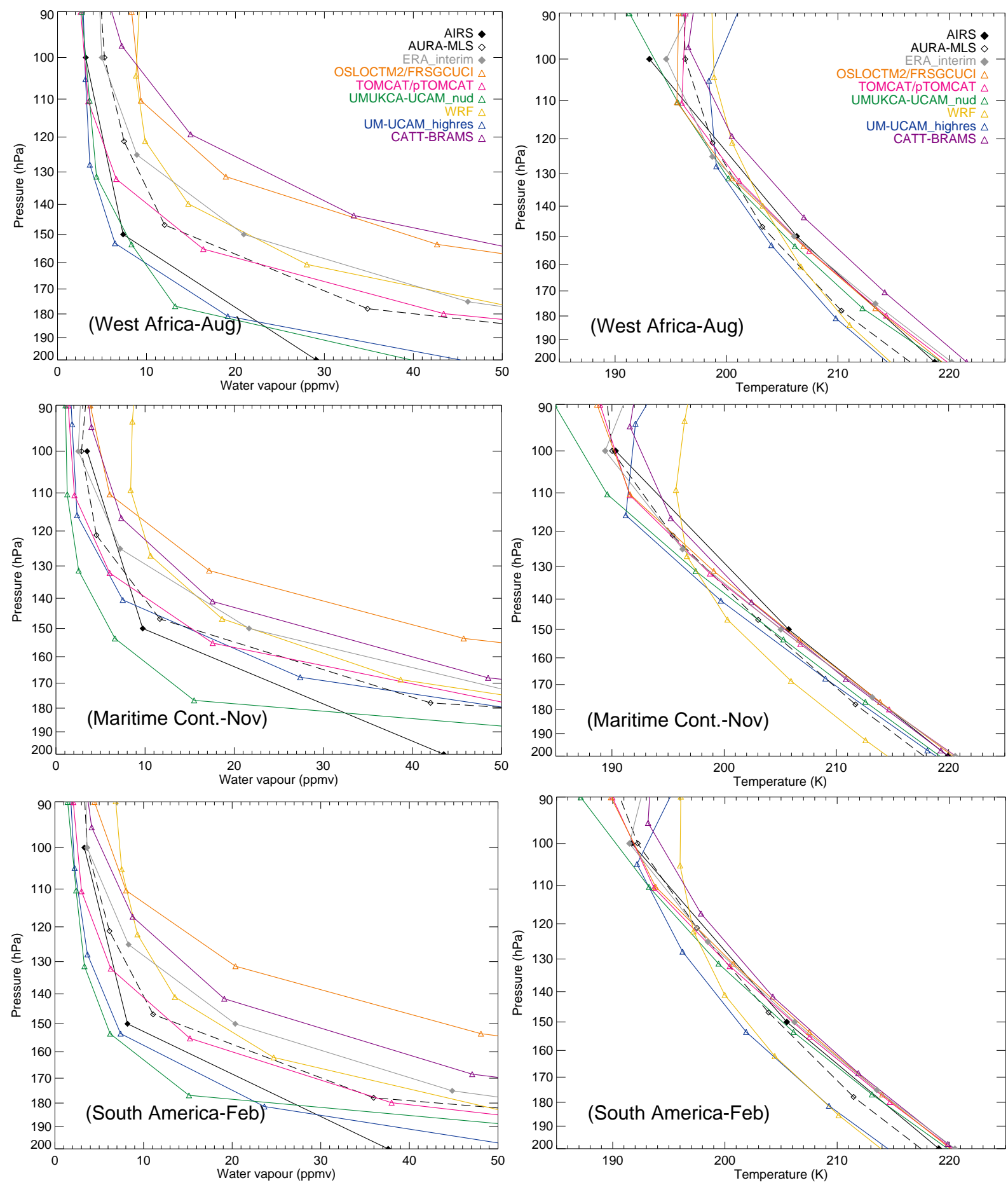

Fig. 10. Monthly mean profiles of water vapour mixing ratio and temperature from observations (AIRS and AURA-MLS), reanalysis data (ERA-Interim) and model simulations. The profiles are averaged over West Africa in August, the Maritime Continent in November and South America in February. 
areas is not always correctly reproduced by models. The enhanced precipitation rates over the islands and peninsulas of the Maritime Continent are better represented by high resolution models. Some models tend to overestimate precipitation rates and cloud top heights over the ocean regions of the Maritime Continent, and these features seem to be less dependent on the horizontal resolution of the models. The models' inability to correctly capture the land-sea differences in convective activity can have implications on transport whenever short-lived chemical species have large land-sea contrast in emissions or surface concentrations. This is the case for many important chemical species such as isoprene (emitted over tropical land regions), methyl-iodide and bromoform (emitted in shallow and warm oceanic regions).

The vertical distribution of clouds from three different observational datasets suggests that the Maritime Continent has the largest fraction of clouds reaching above the $Q=0$ level compared to West Africa and South America. The percentage of clouds reaching above $16 \mathrm{~km}$ can be up to 10 times smaller compared to clouds reaching above the $Q=0$ level. For short-lived species, the fast convective transport to the $Q=0$ level, followed by radiative ascent, can provide an effective pathway to the tropical lower stratosphere.

Most models largely underestimate the fractions of midlevel clouds $(3-6 \mathrm{~km})$, with some additionally underestimating the fraction of clouds above $12 \mathrm{~km}$ and others overestimating the fraction of clouds above $13-14 \mathrm{~km}$; however the observed model differences in cloud top heights are not always directly related to differences in the mean height of the convective transport and the latter will be addressed in Hoyle et al. (2010). The implications of these model biases for the chemistry budget of the UTLS will be largest for short-lived species, such as lightning $\mathrm{NO}_{\mathrm{x}}$, or methyliodide, which are most sensitive to fast convective transport due to their short lifetime. Both these chemical species are produced in tropical regions, either in the free troposphere by electrically-active convective storms, or at the ocean surface. Both species have the potential to greatly impact the ozone budget in the UTLS. Due to the large vertical gradient of ozone at the tropical tropopause, the correct representation of the height at which these species are detrained is therefore crucial for models to correctly predict their impact on UTLS ozone.

Acknowledgements. This work has been supported by the integrated European project SCOUT-O3, NCAS-Climate and NCEO (UK). Simulations from the UM, WRF and TOMCAT-based models were performed on the HECToR UK national supercomputing facilities. Technical support for the UM model was provided by NCAS-CMS. The CATT-BRAMS work was supported by the program LEFE/INSU in France (projects UTLS-tropicale and Tropopause 2009) and was performed using HPC resources of CINES under the allocation 2008 - c2008012536 and 2009 c2009015036 made by GENCI (Grand Equipement National de Calcul Intensif). We thank NASA for the TRMM, GPCP, ISCCP, MODIS, AURA-MLS, and AIRS datasets. We thank NOAA for providing CMAP and NOAA OLR datasets.
Edited by: G. Vaughan

\section{References}

Adler, R. F., Huffman, G. J., Chang, A., Ferraro, R., Xie, P., Janowiak, J., Rudolf, B., Schneider, U., Curtis, S., Bolvin, D., Gruber, A., Susskind, J., Arkin, P., and Nelkin, E.: The Version 2 Global Precipitation Climatology Project (GPCP) Monthly Precipitation Analysis (1979-Present), J. Hydrometeor., 4, 11471167, 2003.

Ackerman, S. A., Holz, R. E., Frey, R., Eloranta, E. W., Maddux, B. G., McGill, M.: Cloud Detection with MODIS. Part II: Validation, J. Atmos. Oceanic Technol., 25, 1073-1086, 2008.

Alcala, C. M. and Dessler, A. E.: Observations of deep convection in the tropics using the Tropical Rainfall Measuring Mission (TRMM) precipitation radar, J. Geophys. Res., 107(D24), 4792, doi:10.1029/2002JD002457, 2002.

Arakawa, A. and Schubert, W. H.: Interaction of a cumulus cloud ensemble with the large-scale environment, Part I., J. Atmos. Sci., 31, 674-701, 1974.

Arteta, J., Marécal, V., and Rivière, E. D.: Regional modelling of tracer transport by tropical convection - Part 1: Sensitivity to convection parameterization, Atmos. Chem. Phys., 9, 70817100, doi:10.5194/acp-9-7081-2009, 2009.

Arteta, J., Marécal, V., and Rivière, E. D.: Regional modelling of tracer transport by tropical convection - Part 2: Sensitivity to model resolutions, Atmos. Chem. Phys., 9, 7101-7114, doi:10.5194/acp-9-7101-2009, 2009.

Aumann, H. H., Chahine, M. T., Gautier, C., Goldberg, M. D., Kalnay, E., McMillin, L. M., Revercomb, H., Rosenkranz, P. W., Smith, W. L., Staelin, D. H., Strow, L. L., Susskind, J.: AIRS/AMSU/HSB on the Aqua mission: design, science objectives, data products, and processing systems, IEEE Trans. Geosci. Remote Sens., 41, 253-264, 2003.

Barret, B., Williams, J. E., Bouarar, I., Yang, X., Josse, B., Law, K., Pham, M., Le Flochmoën, E., Liousse, C., Peuch, V. H., Carver, G. D., Pyle, J. A., Sauvage, B., van Velthoven, P., Schlager, H., Mari, C., and Cammas, J.-P.: Impact of West African Monsoon convective transport and lightning $\mathrm{NO}_{\mathrm{x}}$ production upon the upper tropospheric composition: a multi-model study, Atmos. Chem. Phys., 10, 5719-5738, doi:10.5194/acp-10-57192010, 2010.

Berntsen, T., Fuflestvedt, Myhre, G., Stordal, F., and Berglen, T. F.: Abatement of greenhouse gases: does location matter?, Climatic Change, 74, 377-411, doi:10.1007/s10584-006-0433-4, 2006.

Berthet, G., Esler, J. G., and Haynes, P. H.: A Lagrangian perspective of the tropopause and the ventilation of the lowermost stratosphere, J. Geophys. Res., 112, D18102, doi:10.1029/2006JD008295, 2007.

Bowman, K. P.: Comparison of TRMM precipitation retrievals with rain gauge data from ocean buoys, J. Clim., 18, 178-190, 2005.

Cairo, F., Pommereau, J. P., Law, K. S., Schlager, H., Garnier, A., Fierli, F., Ern, M., Streibel, M., Arabas, S., Borrmann, S., Berthelier, J. J., Blom, C., Christensen, T., D’Amato, F., Di Donfrancesco, G., Deshler, T., Diedhiou, A., Durry, G., Engelsen, O., Goutail, F., Harris, N. R. P., Kerstel, E. R. T., Khaykin, S., Konopka, P., Kylling, A., Larsen, N., Lebel, T., Liu, X., MacKenzie, A. R., Nielsen, J., Oulanowski, A., Parker, D. J., Pelon, J., 
Polcher, J., Pyle, J. A., Ravegnani, F., Rivière, E. D., Robinson, A. D., Röckmann, T., Schiller, C., Simões, F., Stefanutti, L., Stroh, F., Some, L., Siegmund, P., Sitnikov, N., Vernier, J. P., Volk, C. M., Voigt, C., von Hobe, M., Viciani, S., and Yushkov, V.: An introduction to the SCOUT-AMMA stratospheric aircraft, balloons and sondes campaign in West Africa, August 2006: rationale and roadmap, Atmos. Chem. Phys., 10, 2237-2256, doi:10.5194/acp-10-2237-2010, 2010.

Chemel, C., Russo, M. R., Pyle, J. A., Sokhi, R. S., and Schiller, C.: Quantifying the Imprint of a Severe Hector Thunderstorm during ACTIVE/SCOUT-O3 onto the Water Content in the Upper Troposphere/Lower Stratosphere, Mon. Weather Rev., 137(8), 2493-2514, 2009.

Chipperfield, M.: New version of the TOMCAT/SLIMCAT offline chemical transport model: intercomparison of stratospheric tracer experiments, Q. J. R. Meteorol. Soc., 132, 1179-1203, doi:10.1256/qj.05.51, 2006.

Dequé, M., Dreveton, C., Braun, A., and Cariolle, D.: The ARPEGE/IFS atmosphere model: a contribution to the French community climate modelling, Clim. Dyn., 10, 249-266, 1994.

Dessens, O., Zeng, G., Warwick, N. J., and Pyle, J. A.: Short-lived bromine compounds in the lower stratosphere; impact of climate change on ozone, Atmos. Sci. Lett., 10(3), 201-206, 2009.

Divakarla, M. G., Barnet, C. D., Goldberg, M. D., McMillin, L. M., Maddy, E., Wolf, W., Zhou, L., and Liu, X.: Validation of Atmospheric Infrared Sounder temperature and water vapor retrievals with matched radiosonde measurements and forecasts, J. Geophys. Res., 111, D09S15, doi:10.1029/2005JD006116, 2006.

Feng, W., Chipperfield, M. P., Dhomse, S., Monge-Sanz, B. M., Yang, X., Zhang, K., and Ramonet, M.: Evaluation of cloud convection and tracer transport in a three-dimensional chemical transport model, Atmos. Chem. Phys. Discuss., 10, 2295322991, doi:10.5194/acpd-10-22953-2010, 2010.

Folkins, I., Loewenstein, M., Podolske, J., Oltmans, S. J., and Proffitt, M.: A barrier to vertical mixing at $14 \mathrm{~km}$ in the tropics: evidence from ozonesondes and aircraft measurements, J. Geophys. Res., 104, D18, 22095-22102, 1999.

Freitas, S. R., Longo, K. M., Silva Dias, M. A. F., Chatfield, R., Silva Dias, P., Artaxo, P., Andreae, M. O., Grell, G., Rodrigues, L. F., Fazenda, A., and Panetta, J.: The Coupled Aerosol and Tracer Transport model to the Brazilian developments on the Regional Atmospheric Modeling System (CATT-BRAMS) - Part 1: Model description and evaluation, Atmos. Chem. Phys., 9, 28432861, doi:10.5194/acp-9-2843-2009, 2009.

Fritsch, J. and Chappell. C.: Numerical prediction of convectively driven mesoscale pressure systems. I: Convective parameterization, J. Atmos. Sci., 37, 1722-1733, 1980.

Fueglistaler, S., Wernli, H., and Peter, T.: Tropical troposphereto-stratosphere transport inferred from trajectory calculations, J. Geophys. Res., 109, D03108, doi:10.1029/2003JD004069, 2004.

Fueglistaler, S., Dessler, A., Dunkerton, T. J., Folkins, I., Fu, Q., and Mote, P. W.: The tropical tropopause layer, Rev. Geophys., 47, RG1004, doi:10.1029/2008RG000267, 2009.

Gettelman, A. and de F. Forster, P. M.: A climatology of the tropical tropopause layer, J. Met. Soc. Jpn., 80, 911-942, 2002.

Gettelman, A., Salby, M. L., and Sassi, F.: The distribution and influence of convection in the tropical tropopause region, J. Geophys. Res., 107, 1-12, 2002.

Gettelmann A., de F. Forster, P. M., Fujiwara, M., Fu, O., Vömel,
H., Gohar, L. K., Johanson, C., and Ammerman, M.: Radiation balance of the tropical tropopause layer, J. Geophys. Res., 109, D07103, doi:10.1029/2003JD004190, 2004.

Gregory, D. and Rowntree, P.: A mass flux convection scheme with representation of cloud ensemble characteristics and stabilitydependent closure, Mon. Weather Rev., 118, 1483-1506, 1990.

Grell, G. A.: Prognostic evaluation of assumptions used by cumulus parameterizations, Mon. Weather Rev., 121, 764-787, 1993.

Grell, G. A. and Dévényi, D.: A generalized approach to parameterizing convection combining ensemble and data assimilation, Geophys. Res. Lett., 29, 1693, doi:10.1029/2002GL015311, 2002.

Grosvenor, D. P., Choularton, T. W., Coe, H., and Held, G.: A study of the effect of overshooting deep convection on the water content of the TTL and lower stratosphere from Cloud Resolving Model simulations, Atmos. Chem. Phys., 7, 4977-5002, doi:10.5194/acp-7-4977-2007, 2007.

Gruber, A. and Krueger, A. F.: The status of NOAA outgoing longwave radiation data set, B. Am. Meteor. Soc., 65, 958-962, 1984.

Highwood, E. J. and Hoskins, B. J.: The tropical tropopause, Q. J. Roy. Meteorol. Soc., 124, 1579-1604, 1998.

Hong, G., Heygster, G., Notholt, J. and Buehler, S. A.: Interannual to Diurnal Variations in Tropical and Subtropical Deep Convective Clouds and Convective Overshooting from Seven Years of AMSU-B Measurements, J. Clim., 21, 4168-4189, 2008.

Hong, S.-Y. and Lim J.-O. J.: The WRF single-moment 6-class microphysics scheme (WSM6), J. Korean Meteorol. Soc., 42, 129151, 2006.

Hosking, J. S., Russo, M. R., Braesicke, P., and Pyle, J. A.: Modelling deep convection and its impacts on the tropical tropopause layer, Atmos. Chem. Phys. Discuss., 10, 2026720302, doi:10.5194/acpd-10-20267-2010, 2010.

Hossaini, R., Chipperfield, M. P., Monge-Sanz, B. M., Richards, N. A. D., Atlas, E., and Blake, D. R.: Bromoform and dibromomethane in the tropics: a 3-D model study of chemistry and transport, Atmos. Chem. Phys., 10, 719-735, doi:10.5194/acp10-719-2010, 2010.

Hoyle, C. R., Marécal, V., Russo, M. R., Arteta, J., Chemel, C., Chipperfield, M. P., D’Amato, F., Dessens, O., Feng, W., Harris, N. R. P., Hosking, J. S., Morgenstern, O., Peter, T., Pyle, J. A., Reddmann, T., Richards, N. A. D., Telford, P. J., Tian, W., Viciani, S., Wild, O., Yang, X., and Zeng, G.: Tropical deep convection and its impact on composition in global and mesoscale models - Part 2: Tracer transport, Atmos. Chem. Phys. Discuss., 10, 20355-20404, doi:10.5194/acpd-10-20355-2010, 2010.

Huffman, G. J., Adler, R. F., Morrissey, M., Bolvin, D. T., Curtis, S., Joyce, R., McGavock, B., and Susskind, J.: Global precipitation at one-degree daily resolution from multi-satellite observations, J. Hydrometeor., 2, 36-50, 2001.

Illingworth, A. J., Hogan, R. J., O'Connor, E. J., Bouniol, D., Brooks, E. M., Delanoe, J., Donovan, D. P., Eastment, J. D., Gaussiat, N., Goddard, J. W. F., Haeffelin, M., Klein Baltink, H., Krasnov, O. A., Pelon, J., Piriou, J.-M., Protat, A., Russchenberg, H. W. J., Seifert, A., Tompkins, A. M., Van Zadelhoff, G.-J., Vinit, F., Willen, U., Wilson, D. R., and Wrench, C. L.: Cloudnet: Continuous evaluation of cloud profiles in seven operational models using ground-based observations, B. Am. Meteor. Soc., 88, 883-898, 2007.

Janjic, Z.: The Step-Mountain ETA Coordinate model - further 
developments of the convection, viscous sublayer, and turbulence closure schemes, Mon. Weather Rev., 122, 927-945, 1994.

Janjic, Z.: Comments on "Development and evaluation of a convection scheme for use in climate models", J. Atmos. Sci., 57, p. $3686,2000$.

Kain, J. S. and Fritsch, J. M.: A one-dimensional entraining/detraining plume model and its application in convective parameterization, J. Atmos. Sci., 47, 2784-2802, 1990.

Kelley, O. A., Stout, J., Summers, M. and Zipser, E. J.: Do the Tallest Convective Cells over the Tropical Ocean Have Slow Updrafts?, Mon. Weather Rev., 138, 1651-1672, 2010

King, M. D., Menzel, W. P., Kaufman, Y. J., Tanre, D., Gao, B. C., Platnick, S., Ackerman, S. A., Remer, L. A., Pincus, R., and Hubanks, P. A.: Cloud and aerosol properties, precipitable water, and profiles of temperature and water vapor from MODIS, IEEE Trans. Geo. Rem. Sens., 41, 442-458, 2003.

Koster, R. D., Dirmeyer, P. A., Guo, Z. C., Bonan, G., Chan, E., Cox, P., Gordon, C. T., Kanae, S., Kowalczyk, E., Lawrence, D., Liu, P., Lu, C.-H., Malyshev, S., McAvaney, B., Mitchell, K., Mocko, D., Oki, T., Oleson, K., Pitman, A., Sud, Y. C., Taylor, C. M., Verseghy, D., Vasic, R., Xue, Y., Yamada, T.: Regions of strong coupling between soil moisture and precipitation, Science, 305(5687), 1138-1140, 2004.

Kummerow, C., Olson, W. S., and Giglio, L.: A Simplified Scheme for Obtaining Precipitation and Vertical Hydrometeor Profiles from Passive Microwave Sensors, IEEE T. Geosci. Remote, 34, 1213-1232, 1996.

Kummerow, C. , Barnes, W., Kozu, T., Shiue, J., and Simpson, J.: The Tropical Rainfall Measuring Mission (TRMM) Sensor Package, J. Atmos. Ocean Tech., 15, 808-816, 1998.

Lawrence, M. G. and Rasch, P. J.: Tracer transport in deep convective updrafts: plume ensemble versus bulk formulations, J. Atmos. Sci., 62, 2880-2894, 2005.

Levine, J. G., Braesicke, P., Harris, N. R. P., Savage, N. H., and Pyle, J., A.: Pathways and timescales for tropospheretostratosphere transport via the tropical tropopause layer and their relevance for very short lived substances, J. Geophys. Res., 112, D04308, doi:10.1029/2005JD006940, 2007.

Liao, X., Rind, D., and Rossow, W. B.: Comparison between SAGE II and ISCCP high-level clouds 1 . Global and zonal mean cloud amounts, J. Geophys. Res., 100, 1121-1135, 1995.

Liao, X., Rind, D., and Rossow, W. B.: Comparison between SAGE II and ISCCP high-level clouds, Part II: Locating cloud tops, J. Geophys. Res., 100, 1137-1147, 1995.

Liebmann, B. and Smith, C. A.: Description of a Complete (Interpolated) Outgoing Longwave Radiation Dataset, B. Am. Meteor. Soc., 77, 1275-1277, 1996.

Liu, C. and Zipser, E. J.: Global distribution of convection penetrating the tropical tropopause, J. Geophys. Res., 110, D23104, doi:10.1029/2005JD006063, 2005.

Liu, C. T.: Geographical and seasonal distribution of tropical tropopause thin clouds and their relation to deep convection and water vapor viewed from satellite measurements, J. Geophys. Res.-Atmos., 112, D09205, doi:10.1029/2006JD007479, 2007.

Liu, C., Zipser, E. J., and Nesbitt, S. W.: Global Distribution of Tropical Deep Convection: Different Perspectives from TRMM Infrared and Radar Data, J. Clim., 20, 489-503, 2007.

Luo, Z., Liu, G. Y., and Stephens, G. L.: CloudSat adding new insight into tropical penetrating convection, Geophys. Res. Lett.,
35, L19819, doi:10.1029/2008GL035330, 2008

Mapes, B. E., Warner, T. T., XU, M., and Gochis, D. J.: Comparison of cumulus parameterizations and entrainment using domainmean wind divergence ain a regional model, J. Atmos. Sci., 61, 1284-1295, 2004.

McFarlane, S. A., Mather, J. H., and Ackerman, T. P.: Analysis of tropical radiative heating profiles: A comparison of models and observations, J. Geophys. Res., 112, D14218, doi:10.1029/2006JD008290, 2007

Marécal, V., Rivière, E. D., Held, G., Cautenet, S., and Freitas, S.: Modelling study of the impact of deep convection on the utls air composition - Part I: Analysis of ozone precursors, Atmos. Chem. Phys., 6, 1567-1584, doi:10.5194/acp-6-1567-2006, 2006.

Neale, R. and Slingo, J.: The Maritime Continent and its role in the global climate: a GCM study, J. Clim., 16, 834-848, 2003.

Parker, D., Jackson, M., and Horton, E.: The 1961-1990 GISST2.2 sea surface temperature and sea ice climatology, Tech. rep., Climate Research Technical, Note No. 63, 1995.

Petch, J., Willet, M., Wong, R. and Woolnough, S.: Modelling suppressed and active convection. Comparing a numerical weather prediction, cloud-resolving and single-column model, Q. J. Roy. Meteorol. Soc., 133, 1807-1100, 2007.

Pickering, K. E., Thompson, A. M., Wang, Y., Tao, W.-K., McNamara, D. P., Kirchhoff, V. W. J. H., Heikes, B. G., Sachse, G. W., Bradshaw, J. D., Gregory, G. L., and Blake, D. R.: Convective transport of biomass burning emissions over Brazil during TRACE A, J. Geophys. Res., 101(D19), 23993-24012, 1996.

Pommereau, J.-P., Garnier, A., Held, G., Gomes, A.-M., Goutail, F., Durry, G., Borchi, F., Hauchecorne, A., Montoux, N., Cocquerez, P., Letrenne, G., Vial, F., Hertzog, A., Legras, B., Pisso, I., Pyle, J. A., Harris, N. R. P., Jones, R. L., Robinson, A., Hansford, G., Eden, L., Gardiner, T., Swann, N., Knudsen, B., Larsen, N., Nielsen, J., Christensen, T., Cairo, F., Pirre, M., Marécal, V., Huret, N., Riviére, E., Coe, H., Grosvenor, D., Edvarsen, K., Di Donfrancesco, G., Ricaud, P., Berthelier, J.-J., Godefroy, M., Seran, E., Longo, K., and Freitas, S.: An overview of the HIBISCUS campaign, Atmos. Chem. Phys. Discuss., 7, 2389-2475, doi:10.5194/acpd-7-2389-2007, 2007.

Pope, V. D., Pamment, J. A., Jackson, D. R., and Slingo, A.: The representation of water and its dependence on vertical resolution in the Hadley Centre climate model, J. Climate, 14, 3065-3085, 2001.

Quack, B. and Wallace, D. W. R.: Air-sea flux of bromoform: Controls, rates, and implications, Global Biogeochem. Cycles, 17(1), 1023, doi:10.1029/2002GB001890, 2003.

Rossow, W. B. and Pearl, C.: 22-Year survey of tropical convection penetrating into the lower stratosphere, Geophys. Res. Lett., 34, L04803, doi:10.1029/2006GL028635, 2007.

Rossow, W. B. and Schiffer, R. A.: ISCCP Cloud Data Products, B. Am. Meteor. Soc., 72, 2-20, 1991.

Rossow, W. B., Walker, A. W., and Garder, L. C.: Comparison of ISCCP and Other Cloud Amounts, J. Clim., 6, 2394-2418, 1993.

Rossow, W. B., Walker, A. W., Beuschel, D. E., and Roiter, M. D.: International Satellite Cloud Climatology Project (ISCCP) Documentation of New Cloud Datasets, WMO/TD-No. 737, World Meteorological Organization, 115 pp., 1996.

Ricaud, P., Barret, B., Attié, J.-L., Motte, E., Le Flochmoën, E., Teyssèdre, H., Peuch, V.-H., Livesey, N., Lambert, A., and 
Pommereau, J.-P.: Impact of land convection on tropospherestratosphere exchange in the tropics, Atmos. Chem. Phys., 7, 5639-5657, doi:10.5194/acp-7-5639-2007, 2007.

Rind, D.: Dependence of warm and cold climate depiction on climate model resolution, J. Clim., 1, 965-997, 1988.

Saito, K., Keenan, T., Holland, G., and Puri, K.: Numerical Simulation of the Diurnal Evolution of Tropical Island Convection over the Maritime Continent, Mon. Weather Rev., 129, 378-400, 2001

Salawitch, R. J., Weisenstein, D. K., Kovalenko, L. J., Sioris, C. E., Wennberg, P. O., Chance, K., Ko, M. K. W. and McLinden, C. A.: Sensitivity of ozone to bromine in the lower stratosphere, Geophys. Res. Lett., 32, L05811, doi:10.1029/2004GL021504, 2005.

Savtchenko, A.: Deep convection and upper-tropospheric humidity: A look from the A-Train, Geophys. Res. Lett., 36, L06814, doi:10.1029/2009GL037508, 2009

Schiller, C., Grooß, J.-U., Konopka, P., Plöger, F., Silva dos Santos, F. H., and Spelten, N.: Hydration and dehydration at the tropical tropopause, Atmos. Chem. Phys., 9, 9647-9660, doi:10.5194/acp-9-9647-2009, 2009.

Sherwood, S. C. and Dessler, A. E.: A model for transport across the tropical tropopause, J. Atmos. Sci., 58, 765-779, 2001.

Simmons, A. J., Uppala, S., Dee, D. and Kobayashi, S.: 2007: ERAInterim: New ECMWF reanalysis products from 1989 onwards, ECMWF Newsletter, No. 110, ECMWF, Reading, UK, 25-35, 2007

Skamarock, W. C., Klemp, J. B., Dudhia, J., Gill, D. O., Barker, D. M., Duda, M. G., Huang, X.-Y., Wang, W., and Powers, J. G.: A description of the Advanced Research WRF Version 3, NCAR Technical Note NCAR/TN-475+STR, NCAR, NCAR Boulder, CO, USA, 2008.

Solomon, S., Rosenlof, K. H., Portmann, R. W., Daniel, J. S., Davis, S. M., Sanford, T. J. and Plattner, G.-K.: Contributions of Stratospheric Water Vapor to Decadal Changes in the Rate of Global Warming, Science, 327, 1219-1223, 2010.

Stockwell, D. Z. and Chipperfield, M.P.: A tropospheric chemical transport model: development and validation of the model transport schemes, Q. J. Roy. Meteor. Soc., 125, 1747-1783, 1999.

Sukoriansky, S., Galperin, B., and Staroselsky, I.: A quasinormal scale elimination model of turbulent flows with stable stratification, Phys. Fluids, 17, 085107, doi:10.1063/1.2009010, 2005.

Susskind, J., Barnet, C. D., and Blaisdell, J. M., Retrieval of atmospheric and surface parameters from AIRS/AMSU/HSB data in the presence of clouds, IEEE Trans, Geosci. Remote Sens., 41, 390-409, 2003.

Telford, P. J., Braesicke, P., Morgenstern, O., and Pyle, J. A.: Technical Note: Description and assessment of a nudged version of the new dynamics Unified Model, Atmos. Chem. Phys., 8, 17011712, doi:10.5194/acp-8-1701-2008, 2008.

Tian, B., Soden, B. J. and Wu, X.: Diurnal cycle of convection, clouds, and water vapor in the tropical upper troposphere: Satellites versus a general circulation model, J. Geophys. Res., 109, D10101, doi:10.1029/2003JD004117, 2004.
Tian, B., Held, I. M., Lau, N.-C., and Soden, B. J.: Diurnal cycle of summertime deep convection over North America: A satellite perspective, J. Geophys. Res., 110, D10108, doi:10.1029/2004JD005275, 2005.

Tiedtke, M.: A comprehensive mass flux scheme for cumulus parameterization in large scale models, Mon. Weather Rev., 117, 1779-1800, 1989.

Tost, H., Lawrence, M. G., Brühl, C., Jöckel, P., The GABRIEL Team, and The SCOUT-O3-DARWIN/ACTIVE Team: Uncertainties in atmospheric chemistry modelling due to convection parameterisations and subsequent scavenging, Atmos. Chem. Phys., 10, 1931-1951, doi:10.5194/acp-10-1931-2010, 2010.

Vaughan, G., Schiller, C., MacKenzie, A. R., Bower, K., Peter, T., Schlager, H., Harris, N. R. P., and May, P. T.: SCOUTO3/ACTIVE: High-altitude Aircraft Measurements around Deep Tropical Convection, B. Am. Meteorol. Soc., 89, 647-662, 2008.

Walko, R. L., Cotton, W. R., Meyers, M. P. and Harrington, J. Y.: New RAMS cloud microphysics parameterization. Part I: The single-moment scheme, 38, 29-62, 1995.

Wild, O., Sundet, J. K., Prather, M. J., Isaksen, S. A., Akimoto, H., Browell, E. V., and Oltmans, S. J.: Chemical transport model ozone simulations for spring 2001 over the western Pacific: Comparisons with TRACE-P lidar, ozonesondes and Total Ozone Mapping Spectrometer columns, J. Geophys. Res., 108(D21), 8826, doi:10.1029/2002JD003283, 2003.

WMO (World Meteorological Organization): Scientific Assessment of Ozone Depletion: 2006, Global Ozone Research and Monitoring Project Report No. 50, Geneva, Switzerland, 2007.

Wu, D. L., Ackerman, S. A., Davies, R., Diner, D. J., Garay, M. J., Kahn, B. H., Maddux, B. C., Moroney, C. M., Stephens, G. L., Veefkind, J. P. and Vaughan, M. A.: Vertical distributions and relationships of cloud occurrence frequency as observed by MISR, AIRS, MODIS, OMI, CALIPSO, and CloudSat, Geophys. Res. Lett., 36, L09821, doi:10.1029/2009GL037464, 2009.

Wylie, D. P. and Menzel, W. P.: Eight years of global high cloud statistics using HIRS, J. Climate., 12, 170-184, 1999.

Xie, P. and Arkin, P. A.: Global precipitation: A 17-year monthly analysis based on gauge observations, satellite estimates, and numerical model outputs, B. Am. Meteor. Soc., 78, 2539-2558, 1997.

Yano, J.-I.: Deep-convective vertical transport: what is mass flux?, Atmos. Chem. Phys. Discuss., 9, 3535-3553, doi:10.5194/acpd9-3535-2009, 2009.

Zhang, G. J. and McFarlane, N. A.: Sensitivity of climate simulations to the parameterization of cumulus convection in the Canadian Climate Centre General Circulation Model, Atmos. Ocean., 33, 407-446, 1995. 